13, allée François Mitterrand

BP 13633

49100 ANGERS Cedex 01

Tél. : +33 (0) 241962106

Web : http://www.univ-angers.fr/granem

\section{Volatility transmission and volatility impulse response functions in European electricity forward markets}

Yannick Le Pen

LEMNA (Université de Nantes)

Benoît Sévi

GRANEM (Université d'Angers) et LEMNA (Université de Nantes)

Octobre 2008

Document de travail du GRANEM n ${ }^{\circ}$ 2008-02-002 


\title{
Volatility transmission and volatility impulse response functions in European electricity forward markets
}

Yannick Le Pen et Benoît Sévi

Document de travail du GRANEM n²008-02-002

octobre 2008

Classification JEL : C3, G1, Q43.

Mots-clés: fonction impulsion réponse de volatilité, GARCH multivarié, marché forward de l'électricité, transmission de volatilité

Keywords: volatility impulse response function, multivariate $\mathrm{GARCH}$, electricity forward markets, volatility spillovers

Résumé : A l'aide de données quotidiennes sur la période mars 2001 à juin 2005, nous estimons un modèle VAR-BEKK et montrons l'existence de transmissions au niveau des rendements et des volatilités entre les marchés forward de l'électricité pour l'Allemagne, les Pays-Bas et la Grande-Bretagne. Nous appliquons la fonction VIRF de Hafner and Herwartz [2006, Journal of International Money and Finance 25, 719-740] afin de mesurer l'impact d'un choc sur la volatilité conditionnelle. Nous observons qu'un choc a un impact positif important seulement si son amplitude est grande en regard du niveau de la volatilité à cet instant. Finalement, nous estimons la densité des fonctions VIRF pour différents horizons de prévisions. Ces distributions lissées sont asymétriques et montrent que des évènements extrêmes sont possibles même si leur probabilité est faible. Ces résultats ont des implications intéressantes pour les participants au marché dont la politique de gestion des risques est basée sur les prix des options, eux-mêmes dépendant du niveau de volatilité.

Abstract: Using daily data from March 2001 to June 2005, we estimate a VAR-BEKK model and find evidence of return and volatility spillovers between the German, the Dutch and the British forward electricity markets. We apply Hafner and Herwartz [2006, Journal of International Money and Finance 25, 719-740] Volatility Impulse Response Function (VIRF) to quantify the impact of shock on expected conditional volatility. We observe that a shock has a high positive impact only if its size is large compared to the current level of volatility. The impact of shocks is usually not persistent, which may be an indication of market efficiency. Finally, we estimate the density of the VIRF at different forecast horizon. These fitted distributions are asymmetric and show that extreme events are possible even if their probability is low. These results have interesting implications for market participants whose risk management policy is based on option prices which themselves depend on the volatility level.

\author{
Yannick Le Pen \\ Institut d'Economie et de Management de Nantes - IAE \\ Université de Nantes \\ yannick.le-pen@univ-nantes.fr
}

Benoît Sévi

Faculté de Droit, Economie et Gestion

Université d'Angers

benoit.sevi@gmail.com

( 2008 by Yannick Le Pen and Benoît Sévi. All rights reserved. Short sections of text, not to exceed two paragraphs, may be quoted without explicit permission provided that full credit, including $\odot$ notice, is given to the source.

๑ 2008 by Yannick Le Pen et Benoît Sévi. Tous droits réservés. De courtes parties du texte, n’excédant pas deux paragraphes, peuvent être citées sans la permission des auteurs, à condition que la source soit citée. 


\title{
Volatility transmission and volatility impulse response func- tions in European electricity forward markets ${ }^{1}$
}

\author{
Yannick Le Pen ${ }^{2}$ \\ Université de Nantes (LEM)
}

Benoît Sévi ${ }^{3}$

Université d'Angers (GRANEM) and LEM

November 14, 2008

\begin{abstract}
Using daily data from March 2001 to June 2005, we estimate a VAR-BEKK model and find evidence of return and volatility spillovers between the German, the Dutch and the British forward electricity markets. We apply Hafner and Herwartz [2006, Journal of International Money and Finance 25, 719-740] Volatility Impulse Response Function (VIRF) to quantify the impact of shock on expected conditional volatility. We observe that a shock has a high positive impact only if its size is large compared to the current level of volatility. The impact of shocks are usually not persistent, which may be an indication of market efficiency. Finally, we estimate the density of the VIRF at different forecast horizon. These fitted distributions are asymmetric and show that extreme events are possible even if their probability is low. These results have interesting implications for market participants whose risk management policy is based on option prices which themselves depend on the volatility level.
\end{abstract}

JEL Classification: C3, G1, Q43.

Keywords: volatility impulse response function, GARCH, non Gaussian distributions, electricity market, forward markets.

\footnotetext{
${ }^{1}$ Acknowledgements. The authors wish to thank Derek Bunn, Bert Willems for helpful discussions and comments. They also thank participants at the 31st IAEE conference in Istanbul and the UKERC international workshop, St-Anne's College, Oxford and the seminar in the University of Angers. They also thank Colin Mackenzie for his help. The authors are responsible for any errors and shortcomings in this paper.

${ }^{2}$ Address for correspondence: Institut d'Économie et de Management de Nantes - IAE, Université de Nantes, Chemin de la Censive du Tertre, BP 52231, 44322 Nantes cedex 3. tel: 33(0)2-40-14-17-34, fax: 33(0)2-40-14-17-49. Email address: yannick.le-pen@univ-nantes.fr

${ }^{3}$ Address for correspondence: Faculté de Droit, Économie et Gestion, Université d'Angers, 13 allée François Mitterrand, BP 13633, 49036 Angers cedex 01. Email address: benoit.sevi@gmail.com
} 


\section{Introduction}

This paper shows and quantifies the impact of shocks on return volatility in the British, Dutch and German electricity forward markets. To achieve this goal, a multivariate GARCH (MGARCH) model and the volatility impulse response function (VIRF) methodology recently developed by Hafner and Herwartz (2006) are applied to forward (OTC) electricity price data at the daily frequency from January 2001 to June 2005.

European electricity markets have experienced some dramatic changes in recent years. The objective of reaching more cost-reflective prices for the final consumer has led the European Commission to introduce the opening of markets to competition into national laws. ${ }^{4}$ Despite the ideal of a "Contestable Market" being far from attained, progress has been observed in most countries. Even in highly concentrated markets, a wholesale market exists, either in a single place (power exchange) or through bilateral contracts via brokers.

As a consequence of this liberalization, the behavior of electricity prices and returns has been the subject of much attention from the academic community. Numerous econometric studies have examined the dynamic and distributional properties of price and/or return time series in leading electricity wholesale markets ${ }^{5}$. The majority of these studies, surveyed in the next section, are devoted to the analysis of univariate time series. What emerge are some stylized facts characteristic of electricity markets, in particular a very high level of volatility, the presence of jumps, a strong seasonal pattern and the existence of mean-reversion.

In contrast, only a few papers examine the issue of spillovers between returns in several power markets and a minority of them attempt to analyze the transmission of moments higher than the mean. ${ }^{6}$ As noted by Bosco et al. (2007): "[...] post-reform European price series have generally been studied in isolation and the issue of the interdependency in the price dynamics of neighboring markets has largely been ignored." (p. 2). Even so, there has been a considerable interest in the financial literature since the beginning of the 1990s in examining whether or not volatility is transmitted from one market to another. Notable references on this subject are Hamao et al. (1990), Engle et al. (1990), Lin et al. (1994), Karolyi (1995), Koutmos and Booth (1995) and Booth et al. (1997) to cite just a few. In particular, Engle et al. (1990) develop the concepts of "meteor showers" and "heat waves" to describe in the first case volatilities reacting to shocks in other markets and in the second case a volatility process whose estimation is not improved by using innovations in other markets. The first contribution of our paper is to show that volatilities in the three main European electricity markets follow a "meteor shower" process, indicating that unexpected realizations in non-national markets help to predict the volatility in a given national market. This issue has not previously been investigated for the case of European power markets.

\footnotetext{
${ }_{4}^{4}$ An exhaustive information on this subject is available on the European Commission DG Competition web site at: http://ec.europa.eu/comm/competition/sectors/energy/inquiry/index.html

${ }^{5}$ Many of these studies have recently been edited in two books: Bunn (2004) and Weron (2006). The former is mainly dedicated to time series dynamics whereas the latter is more concerned with statistical properties of time series.

${ }^{6} \mathrm{~A}$ multivariate analysis of European power prices is conducted in Bosco et al. (2007) but its aim is to describe the long run behavior of the relationship between electricity markets and natural gas market. Volatility transmission in energy markets is studied in Ewing et al. (2002) who rely on stock indexes of oil and gas companies and Serletis and Shahmoradi (2006) who examine volatility spillovers between gas and electricity prices in Alberta state. To the extent of our knowledge, only one paper (Worthington et al., 2005) investigated volatility spillovers in electricity markets, namely Australian markets.
} 
The second contribution of our paper will be to proceed to a quantification of the impact of a shock on volatility in each market adapting Sims's (1980) impulse response function to the volatility setting. To this end, we employ Hafner and Herwartz' (2006) VIRF methodology. However, impulse response analysis in nonlinear systems leads to significant complexities compared to the linear case. Gallant, Rossi and Tauchen (1993) and Kopp, Pesaran and Potter's (1996) (henceforth KPP) offer two competing definitions of impulse response in non linear models. ${ }^{7}$ The main differences between these two definitions lie in the definition of a realistic shock to the system and the choice of a benchmark against which measuring the impact of the shock. Hafner and Herwartz' (2006) VIRF methodology is an application of KPP definition to the MGARCH framework. A crucial feature of the VIRF is worth stressing from the outset: the impact of a shock depends on the current level of volatility and therefore a given shock will not always increase expected volatility. We develop these points more extensively in section 4 .

The variance forecasting ability shown in our analysis has two main application. Firstly, Fleming et al. $(2001,2003)$ have shown that investors who maximize a mean-variance utility function can achieve a significant benefit when daily rebalancing their portfolio using the estimated conditional covariance matrix. A better understanding of the return volatility process should then allow the improvement of portfolio allocation between forward contracts considered as financial assets. Compared to Fleming et al.'s $(2001,2003)$ assets (stocks, bonds, gold and cash), the forward contracts considered in our paper are far from being liquid, which increases the attractiveness of the VIRF analysis. Investors are given an estimation of the persistence of the volatility, allowing them to limit portfolio moves and subsequent transaction costs, which are dramatically higher for less liquid assets. Secondly, market participants rely heavily on options to cover their positions. It is well-known that options are priced according to the entire price distribution, therefore reinforcing the suitability of VIRF distribution.

Our data set of forward prices comes from a major European energy trader and runs from 03/19/2001 to $06 / 07 / 2005$. Our choice to consider only forward prices is motivated at least by two reasons. The first one is that spot (day-ahead) prices are too heavily influenced by technical considerations, thereby obscuring the financial transmission we are especially interested in in this paper. The second one is that even if bilateral trading is much less transparent than exchange, we can observe that these forward contracts remain the privileged tool for experienced actors in these markets. For instance, Strecker and Weinhardt (2001) show that trading is a great deal larger in OTC markets than in exchanges for the German case. ${ }^{8}$ On can also observe that worldwide attempts to launch organized exchanges for electricity markets have not yet been successful. Several exchanges have collapsed or have been abolished. In addition to the British Pool, the California exchange collapsed in 2001 because of the authorization given to utilities to trade bilaterally. The NYMEX power contracts have been abandoned because of a lack of trading. This leads Wilson (2002) to give the radical conclusion that: "necessity and viability of exchanges remain doubtful" (p. 1327) which gives us another reason to use forward price data in our paper. An additional motivation for the use of forward prices is that they are much less depending on congestion issues. By using data from the nearby contracts following a standard rollover procedure to build a single time series, we greatly exclude volatility transmission due to congestion expectation. ${ }^{9}$

\footnotetext{
${ }^{7}$ Note that the present paper is the first attempt to use generalized impulse response methodology (KPP) for commodity markets.

${ }^{8}$ Other developments on this issue can be found in Smeers (2004) or in Bosco et al. (2006).

${ }^{9}$ Of course, congestion issues exist when trading forward, but our own experience seems to indicate that this is not
} 
We consider three major markets in Europe: Germany, the Netherlands and England and Wales. Our results seem to indicate a noticeable, but short-lived, impact from shocks on conditional volatilities. Empirical evidence of the presence of beneficial strategies for energy traders are highlighted, though no evaluation of these strategies is provided in this paper.

The plan of the rest of the article is as follows. The following section gives some background elements on European wholesale electricity markets and previous contributions studying the time series behavior of electricity prices. Section 3 describes the econometric methodology of VIRF used in conjonction with a multivariate GARCH model. Section 4 provides and discusses results for different historical shocks. In section 5, we present the estimated distributions of the VIRF for different forecast horizons obtained through the simulation of random shocks. Section 6 sums up our main empirical findings along with a few possible areas for future research.

\section{Literature review}

In this section, we give a brief overview of previous works on electricity markets. In the first part, we expose the three different kinds of models used to represent electricity price behavior. In the second part, we focus on the more narrow subject of spillovers between markets and sum up the results obtained until now with time series methods.

\subsection{Models of wholesale electricity markets and forward trading}

The prolific literature on electricity price behavior is made up of three kinds of contributions: equilibrium models, "closed-form" models and time series models. Each of these models succeed in replicating some, but not all, stylized facts about electricity prices. The choice of a model is of critical importance for market participants who wish to manage their financial risk because it has a significant impact on the pricing of derivatives products. In this section, we present these three categories of models and highlight the advantages of using time series for our purpose.

Routledge, Seppi and Spatt (2001) and Bessembinder and Lemmon (2002) are recent examples of equilibrium models devoted to electricity markets. In these models, equilibrium values are obtained endogenously by demand and supply analysis with some assumptions about utility functions of economic agents. Both models cited above are particularly noteworthy because they provide clear intuitions concerning prices and forward premiums behavior. For instance, the model of Routledge et al. (2001) allows for mean-reversion, heteroscedasticity and asymmetries in price probability distribution, which are well-known features of electricity price data. In Bessembinder and Lemmon's (2002) model the forward premium depends on second and third centered moments of demand, which is also a striking empirical finding in electricity markets. Overall, modern equilibrium models provide testable hypotheses, generally in line with reality, but lack practical applications for derivatives pricing. ${ }^{10}$

The second category which regroups "reduced-form 'finance' models" (as coined by Routledge et al., 2001, p. 2) is the one preferred by risk managers. The analytical solutions supplied by these models

immediately integrated at the moment the contract is traded.

${ }^{10}$ We refer the reader to Bühler and Müller-Merbach (2007) for a rigorous and relevant comparison of equilibrium models and reduced-form models. 
are easier to use for the pricing of derivatives, but rely on a stochastic process chosen ex ante. The process has to take into account some particularities of power prices: mean-reversion, price spikes, zero and even negative prices, strong seasonality, among others. A two or even a three-factor model is therefore required to get a good fit of the data. The equilibrium aspect is not present under the form of supply and demand functions but is part of the model through a risk premium for each risk factor of the model.

A Recent example of these models for commodities is Schwartz and Smith (2000) who develop a two-factors model allowing for mean-reversion to an estimated long run mean but also short-term variations $^{11}$. Barlow's (2002) diffusion model is a non-linear Ornstein-Uhlenbeck process allowing for spikes and fitting quite well Alberta's power price series. Lucia and Schwartz's (2002) paper emphasizes the seasonal pattern of power prices in the NordPool, which is a predictable component of price. Two one-factor and two two-factors models along with a sinusoidal function capture this seasonal pattern with a strong mean-reverting effect. Predictability is shown to greatly influence derivatives pricing and is of primary importance because of the impossibility of using the standard cost-of-carry model (see also Eydeland and Geman (1998)). Similarly to Lucia and Schwartz (2002), Escribano et al. (2002) model the behavior of daily spot prices in Argentina, Australia, New Zealand, Scandinavia and Spain with stochastic models mixed with GARCH errors. Their estimations uncover patterns identical to Lucia and Schwartz' findings, namely mean-reversion, jumps and strong seasonality. Huisman and Mahieu (2003) model day-ahead base load prices for the Dutch APX market, the German LPX market ${ }^{12}$ and $^{2}$ the UK market using a regime switching model similar to Lucia and Schwartz (2002). Applied to their data, their model better takes into account the short duration of spikes and the stronger meanreversion after occurrence of a spike than previous stochastic jump processes. ${ }^{13}$ Recently, Geman and Roncoroni (2006) have proposed a family of discontinuous processes featuring upward and downward jumps to model electricity spot prices. These processes allow for mean-reversion and spikes resulting from momentary imbalance between demand and supply. The estimated models fit the data from three US power markets reasonably well and remain sufficiently tractable for pricing and risk management activities.

Time-series models, which we are applying in this paper, make the third category. These models use the statistical features of spot and forward prices and returns in order to fit their conditional mean and covariance matrix. Some exogenous variables can be added to increase their forecast accuracy. Such econometric specifications have been usable in risk management since seminal papers by Engle (1982) and Bollerslev (1986) who provide models of the conditional variance applying ARMA-type structures. Derivatives pricing, as well as portfolio choice and hedge ratio computation then become possible on a time-varying basis. Econometric models are greedy in parameters to estimate but succeed in replicating stylized facts of electricity prices quoted above. Literature on this topic may be roughly divided between: (i) univariate models focusing on a single power return and (ii) multivariate models interested in the joint behavior of electricity markets returns and possibly the issue of price convergence and integration ${ }^{14}$.

${ }^{11}$ The long run mean is estimated through long-maturity futures contracts and short-term variations are derived from differences between short and long-term futures prices.

${ }^{12}$ LPX stands for Leipzig Power Exchange which has merged with the European Energy Exchange (EEX) in 2002.

${ }^{13}$ Very recently, Huisman et al. (2007) have applied an identical model to hourly prices considering the data as a panel. Hourly prices revert to a hourly specific mean price level, which differs over the hours of the day.

${ }^{14}$ We address the multivariate models issue in the second part of this section. 
Among main references for univariate analysis, is Hadsell et al. (2004) whose specification resorts to the TARCH model of Zakoïan (1994) for the modelling of five US spot prices quoted on the NYMEX between 1996 and 2001. ${ }^{15}$ Their findings indicate persistence of volatility with an asymmetric or "leverage effect" in all markets. By decomposing their sample in sub-samples for each year, they put forward a learning effect $\grave{a}$ la Figlewski (1984) (i.e. the newness of the markets could explain the observed decreasing level of volatility. Hadsell and Shawky (2006) study the behavior of power dayahead and retail-time prices in the eleven markets of the New York Independent Systems Operator (NYISO) during the period January 2001 to June 2004. Using a random walk model associated with a $\operatorname{GARCH}(1,1)$ specification for the innovations, it is shown that volatility is higher though less persistent in the real-time market. An interesting finding of the paper is the established relationship between volatility levels and congestion which leads them to note that: "Market participants who are interested in forecasting volatility levels in electricity prices should start with forecasting expected congestion" (p. 173). This is particularly true for day-ahead or real-time pricing but this seems to be less relevant for forward contracts data.

Goto and Karolyi (2004) confirm the features of volatility clustering and jumps for power price data. These authors show that models with seasonality, time-varying conditional volatility and jumps provide a good fit for price series in the US, NordPool and Australia. Despite data coming from markets with very different institutional structures, GARCH attributes and jumps seem to exhibit some similarities, which may be intrinsic to the physical nature of electricity. Byström (2005) resorts to extreme value theory to assess tails thickness in NordPool hourly spot prices. The distribution providing the best fit is the generalized Pareto distribution. Estimates are found to be significantly more accurate than those of standard GARCH models with or without Gaussianity. ${ }^{16}$

A recent work by Rusco and Walls (2005), who focus on the non normality of electricity prices, is of interest for our paper. The authors show that the skew- $t$ and skew normal densities give a better fit for the data of the Californian market between April 1998 and 2000 compared to a normal distribution. In our paper, we retain a Student's t-distribution without an asymmetry parameter for the computation of the log-likelihood in order to take into account the leptokurticity of return data.

Mount et al. (2006) use a regime-switching model to fit the frequent observed spikes. The flexibility of their model comes from the fact that transition probabilities are functions of some exogenous variables, namely load and reserve margin available at daily frequency in the PJM. The estimation of a probability of switching from a low to a high regime is useful for risk management applications because it may improve the traders' ability to forecast spikes.

Koopman et al. (2007) apply a long memory model with GARCH errors and take into account a strong characteristic of power prices, namely their seasonality. Seasonality in power prices is intuitive because of the dependence of demand on weather conditions and business climate. The introduction of periodic coefficients in the mean return equation leads to a better fit of day-ahead prices for NordPool, EEX, Powernext and APX markets. Seasonality is also investigated in Rambharat et al. (2005), who use temperature data to estimate an autoregressive model with mean reversion which seems to outperform stochastic jump diffusion models for the data set considered.

\footnotetext{
${ }^{15}$ Some series begin in 1998 and 1999. See also Hadsell (2006) for an application of the TARCH model to electricity prices.

${ }^{16}$ Extreme value theory is of particular interest for risk management activities as VaR bounds estimates and futurs margin requirements.
} 
To conclude, the most complete study of electricity prices in a restructured environment is perhaps Knittel and Roberts (2005). The authors compare how five different models take into account six identified characteristics of electricity prices: mean reversion, time of day effects, weekend/weekday effects, seasonal effects, volatility clustering, extreme values. Among these models are Lucia and Schwartz' (2002) Ornstein-Uhlenbeck processes for mean reversion, jump-diffusion processes for spikes ${ }^{17}$ and Nelson's (1991) EGARCH model for the leverage effect. These models fit the data differently with significant parameters for the characteristics given above. The study confirms that power spot prices have a positive skew which is larger during periods of high demand variability ( $c f$. Bessembinder and Lemmon, 2002). Results also indicate that the equilibrium model of Routledge et al. (2001) gives accurate predictions because of the strong observed mean reversion. Estimates confirm the presence of an "inverse leverage effect" (electricity price volatility tends to rise more after a positive than a negative shock). The authors suggest that time series models may be a good tool to model electricity prices because of their ability to reproduce volatility clustering. They also emphasize the need of distributions alternative to the Gaussian to give a better fit of the estimated higher moments of the return distribution, more precisely the conditional skewness and kurtosis.

\subsection{Markets spillovers}

The main purpose of our paper is to uncover the links between different power markets. These return and volatility spillovers can be uncovered through time series multivariate models, as shown by some previous works which investigate the relation between prices and/or returns while others are involved in the search of volatility spillovers between markets. De Vany and Walls (1999) study the joint behavior of power spot prices in 11 regional U.S. western markets between 1994 and 1996. ${ }^{18}$ The authors find a unit root in price series in all markets but one. In addition, all market-pairs are cointegrated, which is for the authors a "first evidence on the performance of decentralized markets in pricing transmission and power in an open access environment" (p447). A global pattern of nearly uniform prices seems to emerge despite a complex and apparently inefficient transmission network. Park et al. (2006), using acyclic graph methods, confirmed some findings by De Vany and Walls, namely that a relation exists between prices of distant and "not much" connected regions. ${ }^{19}$

A first comprehensive study on the restructured European electricity prices was made by Bower (2002). Data covers NordPool, the former English Pool and the UKPX market, the Spanish market (OMEL), the German markets (EEX and LPX) and the Dutch market (APX). The author is interested in statistical relations between these markets. A correlation analysis allows him to conclude that the Scandinavian market is working efficiently. Returns in European markets appear to be independent from each other. A cointegration analysis shows that communication between European markets is improving, but since then this part of the paper has been criticized in the literature. ${ }^{20}$ Zachmann (2008) studies to which extent European electricity wholesale day-ahead prices converge towards arbitrage freeness. Using an original set of data on cross-border capacity auctions between Germany, Denmark and the Netherlands, he shows the absence of arbitrage opportunities as soon as congestion costs are

17 Results also are strongly related to those of Lucia and Schwartz (2002).

${ }^{18}$ Their analysis has recently been extended by Dempster et al. (2008).

${ }^{19}$ Some others interesting conclusions concerning causality can be drawn from their study, but for the sake of place, we refer the reader to the original paper.

${ }^{20}$ Boisseleau (2004) and Zachmann (2008) point out that the cointegration approach used in Bower's study is not appropriate because the price series did not contain unit root. 
taken into account. Nevertheless, market transparency and cross-border capacities are far from being sufficient, leading Zachmann to conclude that "Although there has been substantial progress by some members, the EU's goal is yet far off' (p. 1660). Bosco et al. (2007) concentrate on the long run relationship between European power markets using a cointegration analysis. They find evidence of market integration only for neighboring countries. In this paper, we focus on the short run dynamics of these three European forward power returns using data daily data in place of weekday medians as in Bosco et al. (2007).

Worthington et al. (2005) are the first to apply MGARCH models to electricity returns. They use a BEKK model (Engle and Kroner, 1995) to show the transmission of prices and price volatilities in five Australian regional electricity spot markets. Their results show that price transmission is low, but that volatility spillovers are present in nearly all five markets. This conclusion is quite interesting because of the limited nature of the interconnections between these markets. Serletis and Shahmoradi (2006) also resorted to a MGARCH model to investigate the relation between natural gas and electricity markets returns. ${ }^{21}$

\section{Modelling of forward returns and volatilities in three Euro- pean electricity markets}

\subsection{Data}

We consider German, Dutch, and British forward returns for base and peak periods. These markets are three major European electricity markets and quite good examples of deregulated markets. ${ }^{22}$ Our sample covers the time period 03/19/2001 to 06/07/2005 and gathers 1065 daily observations. Returns are computed as the log-difference in daily prices.

These forward prices series are obtained from a major trader of energy commodities in Europe. Each day, the electricity desk reports a weighted average of daily prices for each OTC market. Weights are set in accordance with volume traded at each moment of the day. If no trade occurs, this trader reports his observations about bids and offers on the market. In this respect, the methodology used by our trader is not different from the one employed by financial reporting agencies. ${ }^{23}$ If no bid or offer occurs, the trader reports the Platts' price which is a spread against related products. These price series are made by this trader using a standard rollover procedure using the nearby contract. There is no precise date for the rollover but it is made in such a way to keep data on a contract while significant volume remains. An immediate advantage of our data compared to standard commercially provided data is that dates are not determined in advance and are adapted to the market opinion about the future of the contract.

Graphs of these series are given in appendix A. These graphs clearly show volatility clustering for each return. Some descriptive statistics on these returns are given in table 1 . The mean of each return is almost equal to zero. A more important feature of returns is their skewness and their kurtosis. One can

${ }^{21}$ Emery and Liu (2002) also consider this problematic but without examining moments higher that the mean.

${ }^{22}$ French returns from Powernext are excluded from our analysis because of the particular time series properties. Namely, French returns seem to follow an IGARCH process. Indeed, explosive behavior for volatility is not a good property for the analysis of VIRF.

${ }^{23}$ Heren, Platts, Argus or Bloomberg are major providers of OTC prices data for European energy markets. Note that these information sources are extremely costly for academic purpose. 
observe that German returns' skewness is well above zero which denotes an asymmetric distribution. Skewness is slightly negative for Dutch returns and slightly positive for British returns. For all returns, estimated kurtosis are very large which denotes a fat-tailed distribution. As a consequence, for each series the Jarque-Bera statistics strongly refutes the null hypothesis of a normal distribution. ${ }^{24}$ An application of the ARCH-LM test on each return shows that the hypothesis of a conditional volatility cannot be rejected. ${ }^{25}$

\subsection{Interdependencies in returns}

As a first step, we estimates a VAR with two lags for the vectors of base and peak returns $R_{t}=$ $\left(R_{t}^{g e r}, R_{t}^{n e l}, R_{t}^{u k}\right)^{\prime}$ where $R_{t}^{g e r}, R_{t}^{n e l}$ and $R_{t}^{u k}$ respectively stand for the return of German, Dutch and British forward prices at date t. Usual tests show that residual autocorrelation is cancelled out with two lags.

Estimates are given in table 2 for base returns and table 3 for peak returns. We do not add to our VAR models exogenous variables representing expected congestion on the network as we are using data on forward contracts. We think that the change in volatility of forward returns is mainly the consequence of financial arbitrage not linked to the expected working of the network. The results show that returns are connected but that these dependencies are not the same in base and peak periods. In base period, the German return depends on its two lagged values and on British return with one lag. In peak period, the German return now depends on the Dutch return with one lag and on both lagged British returns. The structure of dependencies for Dutch return is similar for base and peak periods. The Dutch return depends on its own two lagged values and on the German return with one lag and British return with two lags. The British return has the most surprising behavior for it depends on its own lagged values only in base periods. In peak period, the British returns only depends on the German return with one lag. The British return is never affected by the Dutch return. Several conclusions can be drawn for these estimations. The German market affects both Dutch and British returns in base and peak periods. The Dutch market never influences the British market while the British market has an impact on it.

\subsection{Interdependencies in volatilities}

In a second step, we note $\epsilon_{t}$ the $(N \times 1)$ vector of residuals from the previous VAR and define $\Sigma_{t}=E\left(\epsilon_{t} \epsilon_{t}^{\prime} \mid \psi_{t-1}\right)$ its conditional variance covariance matrix where $\psi_{t-1}$ is the information set at date $t-1$. We apply a $\operatorname{BEKK}(1,1)$ model (Engle and Kroner, 1995) to model the behavior of $\Sigma_{t}$

$$
\Sigma_{t}=C_{0} C_{0}^{\prime}+A^{\prime} \epsilon_{t-1} \epsilon_{t-1}^{\prime} A+G^{\prime} \Sigma_{t-1} G
$$

where $C_{0}$ is a $N \times N$ lower triangular matrix and $A$ and $G$ are two $N \times N$ matrices. We make the assumption that the conditional distribution of $\epsilon_{t}$ follows a normal or a Student's t-distribution.

Estimates of this BEKK $(1,1)$ model for base returns are displayed in table 4 for the normal distribution

24 Note that Fiorentini et al. (2004) have only recently shown the validity of the Jarque-Bera test for conditionally heteroscedastic processes.

${ }^{25}$ To save space results are not given in this paper but they are available upon request. The ARCH characteristics can also be investigated using an autocorrelation analysis of the squared returns. These tests confirm the original Engle's ARCH-LM test results. 
and table 5 for the Student's t-distribution. For both distributions, some off-diagonal estimated coefficients of $A$ and $G$ are significant which means that conditional variances are connected, indicating a "meteor showers" process in the Engle et al. (1990) typology. The log-likelihood with a Student's t-distribution is higher than with a normal one which can be interpreted in favor of a Student's tdistribution. Therefore, in the following part, we focus on the $\operatorname{BEKK}(1,1)$ model estimated with a Student's t-distribution. The estimated degree of freedom for the Student's t-distribution is $\hat{\nu}=2.1^{26}$. This value is very low and implies a very high kurtosis in the distribution of returns. Estimated conditional variances and covariances are displayed in graphs 19. All three countries show signs of volatility clustering. The Dutch return has the highest extreme values of the conditional variance while these extreme values are the lowest for the German return. The volatility of the Dutch and the British market increases after year 2003, at the midst of our sample.

For peak returns, estimates of the $\operatorname{BEKK}(1,1)$ with a normal and a Student's t-distribution are respectively displayed in tables 6 and 7. The log-likelihood is also higher with the Student's t-distribution which leads us to prefer this distribution. ${ }^{27}$ Estimated conditional variances and covariances are displayed in graphs 20. The extreme values of conditional variance are highest than with base returns for Germany and the Netherlands. German and Dutch conditional variances changes are synchronous which was not a feature of base returns conditional variances. As previously noted, the British returns conditional variance becomes more erratic in the middle of our sample.

\section{Quantifying the impacts of shocks on volatility}

Once the interdependencies in volatilities in our three markets uncovered, our next step will be to quantify the impacts of shocks throughout markets. To do so, we will use the impulse response analysis, put forward by Sims (1980). We must stress here that our focus is on the impact of shocks on conditional variance of returns and not their conditional mean, which makes a significant difference with the traditional impulse response analysis. While Sims analyses impulse response in linear models, Gallant, Rossi and Tauchen (1993) and Koop, Pesaran and Potter (1996) propose two different definitions of impulse response in nonlinear models. Gallant et al. (1993) define a baseline and evaluate the impact of a deterministic shock added to the initial condition. Their "conditional moment profile" is the difference between the "shocked" and the baseline trajectories. This shock is supposed to be either observable or estimated.

Koop et al. (1996) define the generalized impulse response function (GIRF) as the difference between the mean response of the variable of interest, here volatility, conditional on both history and a shock and the mean response conditioned on history only.

Lin (1997) extends Gallant et al. (1993)'s methodology to multivariate GARCH models while Hafner and Herwartz (2006) follow Koop et al. (1996) and define the VIRF. ${ }^{28}$ Koop et al. (1996) and Hafner and Herwartz (2006) criticize Gallant et al.'s (1993) approach. They argue that finding out a realistic shock is far from reachable, all the more so that we are using high frequency data, the links of causality

\footnotetext{
${ }^{26}$ Note that a Student's t-distribution tends to normality as its degree of freedom $\nu$ increases (or $\nu \geq 30$ ). A value close to 2 indicates a very leptokurtic distribution for the residuals.

${ }^{27}$ Another reason linked to the dynamics of conditional volatility will be given beneath.

${ }^{28}$ So far, VIRF methodology has only been applied in Shields et al. (2005) for macroeconomic purpose and Hafner and Herwartz (2006) on exchange rates.
} 
of which may be much intricate. Devising a baseline scenario is also quite difficult. For instance, a zero shock baseline scenario will produce an artificially increase in volatility for every kind of shock. For these two reasons, they propose to use random shocks drawn from the estimated data generating process and not to include a baseline scenario.

In the following parts of this section, we set up a multivariate GARCH model and remind that a $\operatorname{BEKK}(1,1)$ model is a particular case of this model. Then we describe a way to identify independent shock and present the definition of the VIRF.

\subsection{Multivariate GARCH models}

The $\operatorname{BEKK}(1,1)$ model

$$
\Sigma_{t}=C_{0} C_{0}^{\prime}+A \epsilon_{t-1} \epsilon_{t-1}^{\prime} A+G \Sigma_{t-1}^{\prime} G
$$

is a particular case of the more general multivariate $\operatorname{GARCH}(p, q)$ model written as follows:

$$
\operatorname{vech}\left(\Sigma_{t}\right)=c+\sum_{i=1}^{q} A_{i} \operatorname{vech}\left(\epsilon_{t-i} \epsilon_{t-i}^{\prime}\right)+\sum_{j=1}^{p} B_{j} \operatorname{vech}\left(\Sigma_{t-j}\right)
$$

where $\Sigma_{t}$ stands for the conditional covariance matrix at time $t$, vech () is the operator that stacks the lower fraction of an $N \times N$ matrix into an $N^{*}=N(N+1) / 2$ dimensional vector. $A_{i}$ and $B_{j}$ are parameters matrices each containing $\left(N^{*}\right)^{2}$ parameters and $c$ is a $N^{*}$ vector. We use this vech model to eliminate the variables of the conditional covariance matrix which appear twice.

The relation between the matrices of parameters of the multivariate $\operatorname{GARCH}(1,1)$ and the $\operatorname{BEKK}(1,1)$ models ${ }^{29}$ is:

$$
\begin{aligned}
& A_{1}=L_{N}\left(A^{\prime} \otimes A^{\prime}\right) D_{N} \\
& B_{1}=L_{N}\left(G^{\prime} \otimes G^{\prime}\right) D_{N}
\end{aligned}
$$

\subsection{Identification of independent shocks}

Finding out realistic shocks is crucial for the impulse response analysis in a multivariate framework. The vector of errors $\epsilon_{t}$ shows contemporaneous correlation and therefore one cannot shock one of its component without taking into the changes in the others. A current method to solve this difficulty is to use a Cholesky decomposition of the conditional covariance matrix $\Sigma_{t}=P_{t} P_{t}^{\prime}$, where $P_{t}$ is a lower triangular matrix, and to infer from this a random vector $\xi_{t}=P_{t}^{-1} \epsilon_{t}$ with independent components, zero mean, and identity covariance matrix. However, Cholesky decomposition makes $\xi_{t}$ depend on the ordering of the components of $\epsilon_{t}$. Another solution would be to impose some a priori structure of causality based for instance on economic theory. This method is hard to apply to financial data or other high frequency data because the links of causation are rather unclear.

Hafner and Herwartz (2006) propose to use a Jordan decomposition of $\Sigma_{t}$ in order to obtain independent and identically defined (hence i.i.d.) innovations. The symmetric matrix $\Sigma_{t}^{1 / 2}$ is defined

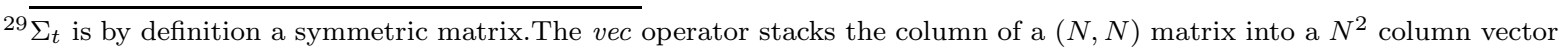
but doesn't eliminate redundant parameters. $L_{N}$ is the elimination matrix such that $\operatorname{vech}(A)=L_{N} \operatorname{vec}(A)$ and $D_{N}$ is the duplication matrix such that $\operatorname{vec}(A)=D_{N} \operatorname{vech}(A)$. 
as:

$$
\Sigma_{t}^{1 / 2}=\Gamma_{t} \Lambda^{1 / 2} \Gamma_{t}^{\prime}
$$

where $\Lambda_{t}=\operatorname{diag}\left(\lambda_{1 t}, \lambda_{2 t}, \ldots, \lambda_{N T}\right)$ is the diagonal matrix whose components $\left\{\lambda_{i, t}\right\}_{i=1}^{N}$ are the eigenvalues of $\Sigma_{t} . \Gamma_{t}=\left(\gamma_{1 t}, \ldots, \gamma_{N t}\right)$ is the matrix $N \times N$ of the corresponding eigenvectors. A vector of independent shocks is defined as $\xi_{t}=\Sigma_{t}^{-1 / 2} \epsilon_{t}$. Hafner and Herwartz show that under the hypothesis of a non Gaussian distribution, $\xi_{t}$ is uniquely defined. This vector of innovation is treated as news, that is to say some independent perturbations unpredictable from the past that affect each markets.

\subsection{Volatility impulse response function}

Hafner and Herwartz (2006) define the VIRF as follows:

$$
V_{h}\left(\xi_{t}, \psi_{t-1}\right)=E\left[\operatorname{vech}\left(\Sigma_{t+h}\right) \mid \xi_{t}, \psi_{t-1}\right]-E\left[\operatorname{vech}\left(\Sigma_{t+h}\right) \mid \psi_{t-1}\right]
$$

where $\xi_{t}$ is a specific shock hitting the system at date $t$ and $\psi_{t-1}$ is the observed history up to $t-1$. The index $h$ represents the forecast horizon. $V_{t}\left(\xi_{h}\right)$ is the $(N(N+1) / 2)$ vector of the impact of the shock on the $h$-ahead conditional covariance matrix components. The VIRF is therefore the difference between the $h$-ahead expected conditional covariance matrix given a shock and history and the expectation given history only.

The VIRF yields an analytical expression of the impulse response function when applied to a the previous class of MGARCH model. Computing the impact of shocks on volatility is therefore less time-consuming compared to a simulation-based estimation. Applied to a MGARCH(1,1) model, the one-step ahead VIRF is:

$$
\begin{aligned}
V_{1}\left(\xi_{t}, \psi_{t-1}\right) & =A_{1}\left\{\operatorname{vech}\left(\Sigma_{t}^{1 / 2} \xi_{t} \xi_{t}^{\prime} \Sigma_{t}^{1 / 2}\right)-\operatorname{vech}\left(\Sigma_{t}\right)\right\} \\
& =A_{1} D_{N}^{+}\left(\Sigma_{t}^{1 / 2} \otimes \Sigma_{t}^{1 / 2}\right) D_{N} \operatorname{vech}\left(\xi_{t} \xi_{t}^{\prime}-I_{N}\right)
\end{aligned}
$$

where $I_{N}$ is the identity matrix, $D_{N}$ is the duplication matrix previously defined and $D_{N}^{+}$its MoorePenrose inverse. For $h>1$, the VIRF is:

$$
\begin{aligned}
V_{h}\left(\xi_{t}, \psi_{t-1}\right) & =\left(A_{1}+B_{1}\right)^{h-1} A_{1} D_{N}^{+}\left(\Sigma_{t}^{1 / 2} \otimes \Sigma_{t}^{1 / 2}\right) D_{N} \operatorname{vech}\left(\xi_{t} \xi_{t}^{\prime}-I_{N}\right) \\
& =\left(A_{1}+B_{1}\right) V_{h-1}\left(\xi_{t}\right)
\end{aligned}
$$

Those expressions show that the VIRF has three properties:

1. The VIRF is an even function: $V_{h}\left(\xi_{t}, \psi_{t-1}\right)=V_{h}\left(-\xi_{t}, \psi_{t-1}\right)$ while impulse response are odd functions in linear analysis.

2. The VIRF is not homogenous of any degree whereas it is in linear analysis.

3. The VIRF depends on history through the volatility state $\Sigma_{t}$ at the time the shock occurs while impulse response do not depend on history in linear analysis.

According to Koop et al.(1996), a more general definition of the VIRF could be proposed if the shock $\xi_{t}$ and the history $\psi_{t-1}$ are considered as realizations of the random variables $\Xi_{t}$ and $\Psi_{t-1}$ respectively:

$$
V_{h}\left(\Xi_{t}, \Psi_{t-1}\right)=E\left[\operatorname{vech}\left(\Sigma_{t+h}\right) \mid \Xi_{t}, \Psi_{t-1}\right]-E\left[\operatorname{vech}\left(\Sigma_{t+h}\right) \mid \Psi_{t-1}\right]
$$


Several choices are therefore allowed. A first one is to consider specific observed shock and history. It is also possible to condition on a particular shock and treat history as random, or to condition on a particular history and allow the shock to be random. A fourth possibility would be to let both shock and history be random. In our application, we decide to analyse the impact of a historical shock given the observed volatility at the date the shock occurs. In this case, our aim is to give some empirical evidence on a past event. The other choice we made is to consider random shocks and an observed conditional covariance variance. A market participant who optimizes his portfolio can evaluate the current level of volatility and he should be more deeply interested in the expectation of future conditional volatility given this level of volatility. In our view allowing for both random shock and history has a limited interest for practical purpose.

\section{Volatility impulse response estimation}

As seen before, the VIRF depends on the conditional covariance matrix $\Sigma_{t}$ at the date the shock happens. The dynamics of shocks is history dependent. We choose different dates in the summer of 2003. The first one is $t_{1}=07 / 09 / 2003$, which is located in a tranquil period (at least in the British market), the second one is the following day $t_{2}=07 / 10 / 2003$ when the British market is hit by a large shock compared to previous values for year 2003. We proceed here as follows: we use the estimated residual $\epsilon_{t}$ and the estimated covariance matrix $\Sigma_{t}$ at the date of the shock and construct standardized residuals $\xi_{t}$ for which we calculate $V_{h}\left(\xi_{t}\right)$. The impulse responses are scaled with respect to the estimated conditional volatilities at the date of the shock. This allows us to interpret the scales as percentage deviations of the "shock scenario" with respect to the "base scenario".

\subsection{Impact of some historical shocks}

\subsubsection{Shocks on volatility for base returns}

For the first date $t_{1}$, the estimated residuals are: $\epsilon_{t_{1}}=(0.0281,0.0270,-0.0005)^{\prime}$ and the vectorized conditional covariance matrix is: $\operatorname{vech}\left(\Sigma_{t_{1}}\right)=(0.9,0.7,0.1,2.4,0.2,0.5)^{\prime} \times 10^{-3}$. Figures 1 depict the time profile of the impulse response of volatilities. This time period can be described as a tranquil period and the shock that hits the returns at this date is not large compared to its previous values for year 2003. Therefore, it's not so surprising to find out that the volatility impulse response is almost null for the German volatility and even negative for the other countries. The effect of the shock cancels out after about 20 days.

The second date $t_{2}=07 / 10 / 2003$ represents another kind of situation. The vector of residuals is $\epsilon_{t_{2}}=$ $(0.0659,-0.0309,0.1078)^{\prime}$ and the vectorized conditional covariance matrix is : $\operatorname{vech}\left(\Sigma_{t_{2}}\right)=(0.9$, $0.8,0.1,2.3,0.3,0.5)^{\prime} \times 10^{-3}$. At this date, the British forward returns is hit by a large shock while the shocks for the other markets are not very different from $t_{1}$. This case gives therefore a second opportunity to assess the extent of volatility transmission through these three markets, when a high shock occurs in one of them.

Figures 2 depict the time profile of the impulse response of volatilities. There is a large positive impact of the shock on all three expected conditional variances. The size of this impact is however not the 

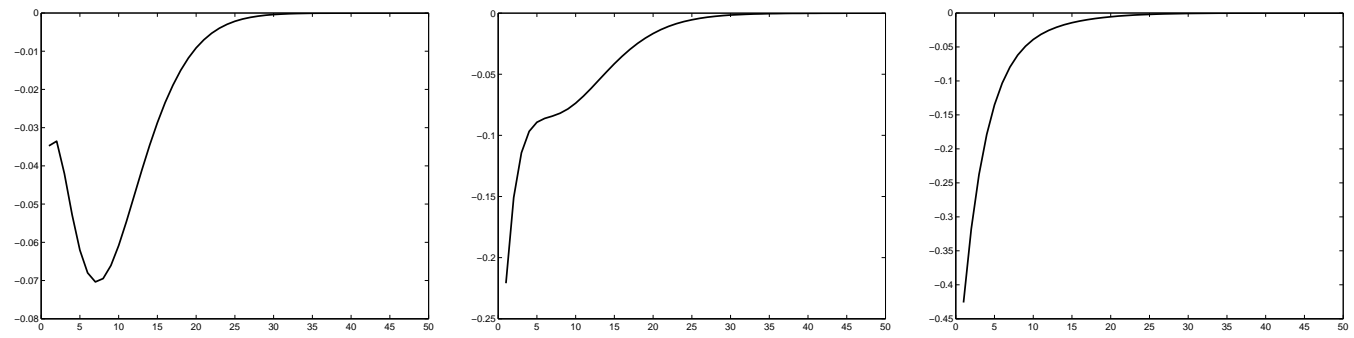

Figure 1: Volatility impulse response function of forward base returns in $t_{1}=07 / 09 / 2003$. From left to right : $R_{t}^{g e r}, R_{t}^{n e l}$ and $R_{t}^{u k}$ variance
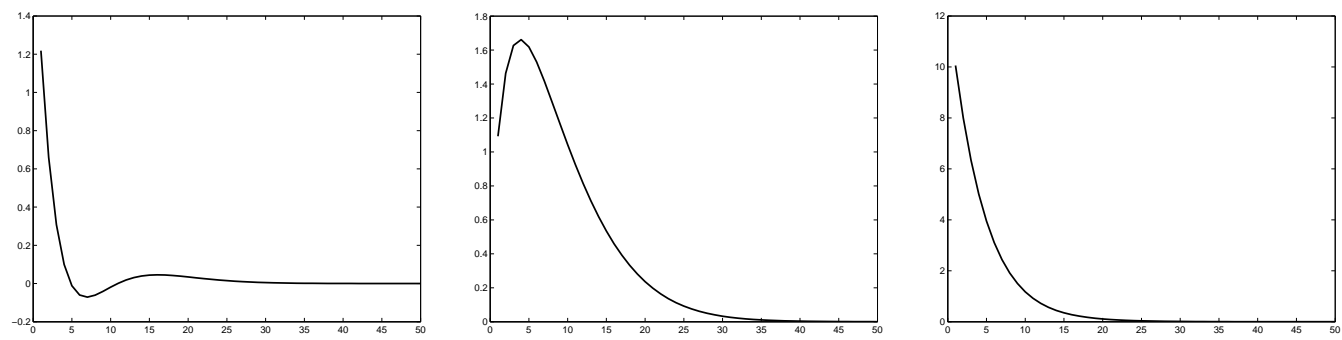

Figure 2: Volatility impulse response function of forward base returns in $t_{2}=07 / 10 / 2003$. From left to right $: R_{t}^{\text {ger }}, R_{t}^{\text {nel }}$ and $R_{t}^{u k}$ variance

same for all countries. The larger increase can be observed for the British return as its one-step ahead expected conditional variance is increased by $1000 \%$. The impact of the shock on the British expected conditional variance vanished after 20 days. The increase in expected conditional variance of the other two countries is about $120 \%$ for the one-step ahead expected conditional variance. The impact of the shock on the German returns conditional variance lasts only 5 days. It reaches it peak on the Dutch conditional variance after five days and disappears after 25 days. To sum up our results, the estimates of the $\operatorname{BEKK}(1,1)$ model clearly indicate that there are volatility transmission between the three markets. The VIRF shows us at least three results. Changes in volatility are driven by domestic shocks and shocks from abroad. Only "large" shocks compared to the current level of volatility will result in an increase in expected conditional volatilities. Another results is that the size and the dynamics of the impact of shock are largely country specific.

\subsubsection{Shocks on volatility for peak returns}

We proceed to the same study for the same dates for forward peak returns. We consider the first date $t_{1}=07 / 09 / 2003$ which is the last day of the tranquil period in the UK in year 2003. At this date, the vector of residual is $\epsilon_{t_{1}}=(0.0240,0.0232,0.0364)^{\prime}$ ' and the vectorized conditional covariance matrix is: $\operatorname{vech}\left(\Sigma_{t_{1}}\right)=(1.2,1.1,0.2,2.3,0.5,1.3)^{\prime} \times 10^{-3}$. The volatility impulse response function are depicted in graphs 3. The impact of this shock on expected conditional volatilities is negative but not very large. Compared to the case of base returns, a striking difference is that the length of the impact is much longer for peak returns. This feature is attributable to the fact that several eigenvalues of the 
matrix $A \otimes A+G \otimes G$ are very close to unity ${ }^{30}$.
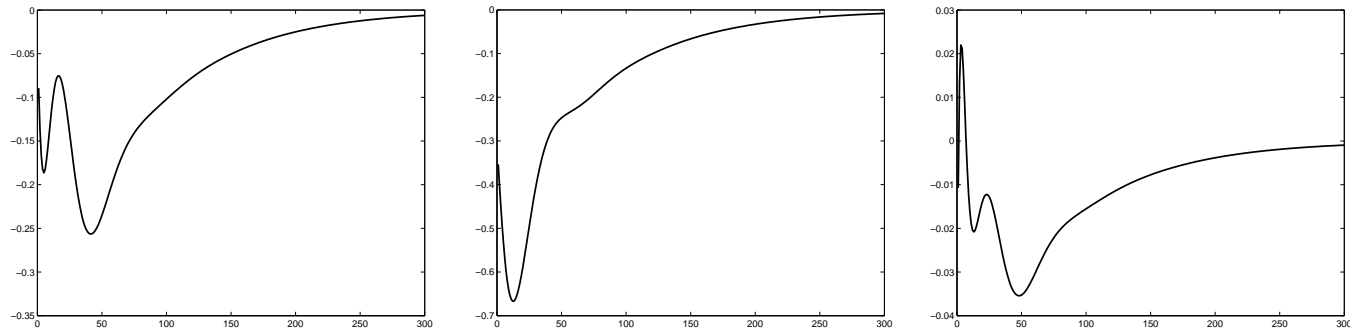

Figure 3: Volatility impulse response function of forward peak returns in $t_{1}=07 / 09 / 03$. From left to right $: R_{t}^{\text {ger }}, R_{t}^{\text {nel }}$ and $R_{t}^{u k}$ variance

The second date $t_{2}=01 / 29 / 03$ marks the beginning of a more volatil period, at least in the British market. The vector of residuals is $\epsilon_{t_{2}}=(0.0653,-0.0694,0.2104)^{\prime}$ ' and the conditional covariance matrix is: $\operatorname{vech}\left(\Sigma_{t_{2}}\right)=(1.4,1.3,0.6,2.4,0.9,1.6)^{\prime} \times 10^{-3}$. Figures 4 depict the impulse response of volatilities for this date. Compared to base returns, the increase in expected conditional variances is higher for the German and the Dutch returns while it is lower for the British return. The impact of the shock on the British conditional volatility quickly cancels while it lasts much longer for the other countries.
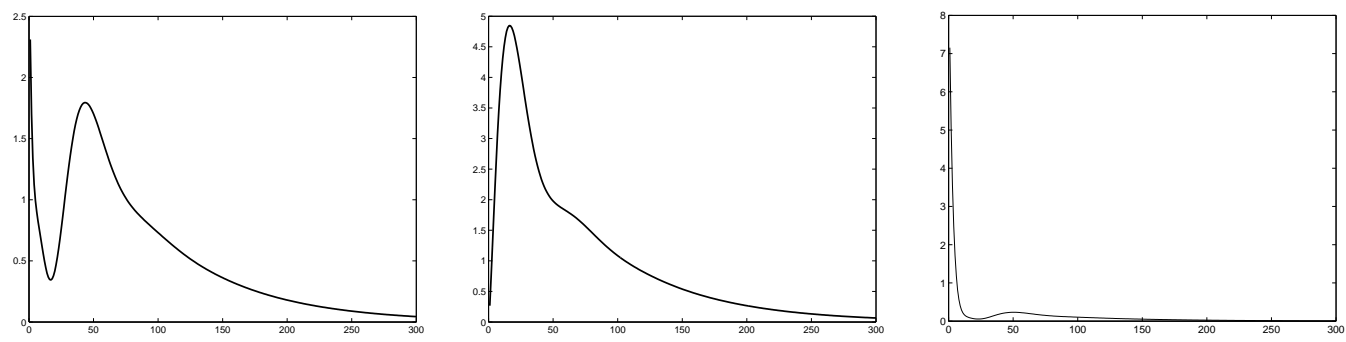

Figure 4: Volatility impulse response function of forward peak returns in $t_{2}=07 / 10 / 03$. From left to right $: R_{t}^{\text {ger }}, R_{t}^{\text {nel }}$ and $R_{t}^{u k}$ variance

\section{$5.2 \quad$ Fitting VIRF distribution}

We now make the assumption that shock and therefore volatility impulse response are random. We simulate 20000 realizations of the shock $\xi_{t}$ from an independent, standardized $t$-distribution with $\nu=2.1$. The VIRF are then computed for each shock according to their formula using the estimated $\operatorname{BEKK}(1,1)$ model with a Student's t-distribution. For two horizons $h=1$ and $h=20$, we estimate the VIRF distribution with a non-parametric kernel density estimator. As the distribution of the VIRF is asymmetric and non Gaussian, we can infer that using only its mean and variance to describe it would entail a loss of information. As noted above, we decide to select some specific history, described by the observed conditional covariance matrix and let the shock be random. This setting corresponds to a situation where we can observe the current state of volatility and want to forecast the change in future

${ }^{30}$ One of the eigenvalues of $A_{1}+B_{1}$ is equal to unity for the normal distribution. By consequence, shocks to volatilities would have an ever-lasting effect which is unrealistic. This fact gives us another reason to select the estimates given by the Student's t-distribution. 
volatility given the possible, still unobserved, shock. We estimate VIRF for the dates $t_{1}=07 / 09 / 03$ and $t_{2}=07 / 10 / 03$.

\subsection{VIRF distribution for forward base returns}

The estimated densities of the impact of a stochastic shock for the date $t_{1}=07 / 09 / 03$ are depicted on graphs 5 and 6 for forecast horizons $h=1$ and $h=20$ respectively. The VIRF distributions are asymmetric and skewed which results from the property that the VIRF is an even function when applied to a BEKK model. One can clearly see from these fitted distribution that the probability of observing a null or negative impact of a shock is high while the probability of a large positive impact is much smaller. As the time horizon increases, the VIRF centres around zero, denoting the cancellation of the impact of the shock.
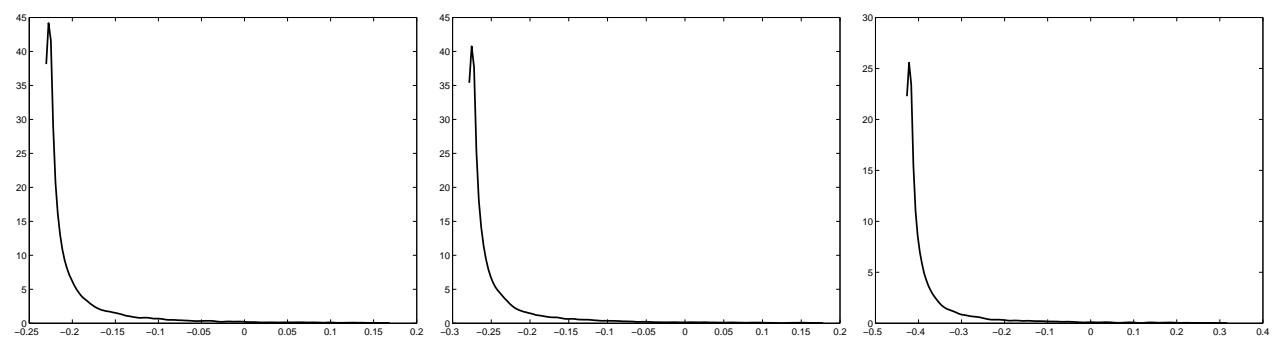

Figure 5: Volatility impulse response function of forward base returns in $t_{1}=07 / 09 / 03$ for a forecast horizon $h=1$. From left to right : $R_{t}^{\text {ger }}, R_{t}^{\text {nel }}$ and $R_{t}^{u k}$ variance
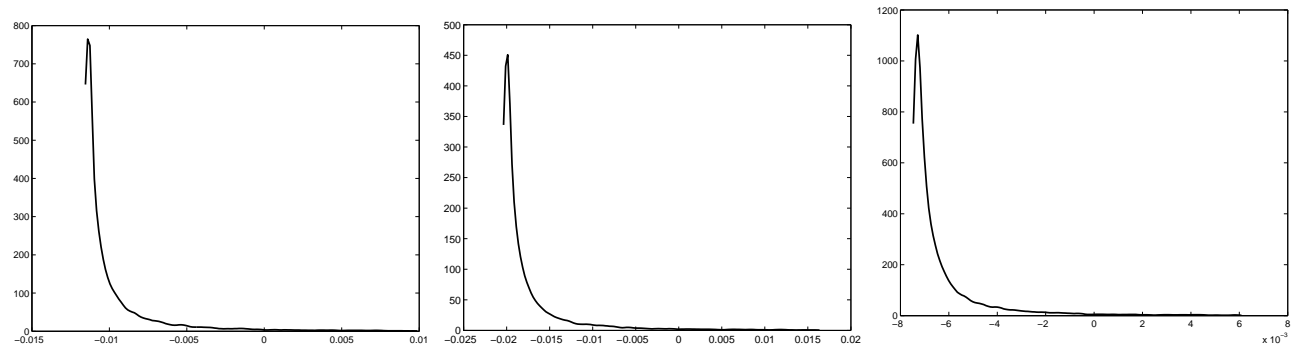

Figure 6: Volatility impulse response function of forward base returns in $t_{1}=07 / 09 / 03$ for a forecast horizon $h=20$. From left to right : $R_{t}^{\text {ger }}, R_{t}^{\text {nel }}$ and $R_{t}^{u k}$ variance

The VIRF fitted distributions for the second date $t_{2}=07 / 10 / 2003$ are displayed in graphs 8 . One can observe that they do not much differ from those for $t_{1}$. For the two dates considered here, the change in initial condition, that is to say the state of volatility before the shock occurs, don't seem to have a large effect on the VIRF distributions. Here again, these densities concentrate around zero as the forecast horizon increases.

\subsection{VIRF distribution for forward peak returns}

The estimated densities of the impact of a stochastic shock for the date $t_{1}=07 / 09 / 03$ are depicted in graph 9 for a forecast horizon $h=1$ and graph 10 for $h=20$. The VIRF distribution are still asymmetric and skewed. The probability of observing a null or negative impact is high. There are however some differences with the VIRF distributions for base returns. The fitted densities tend 

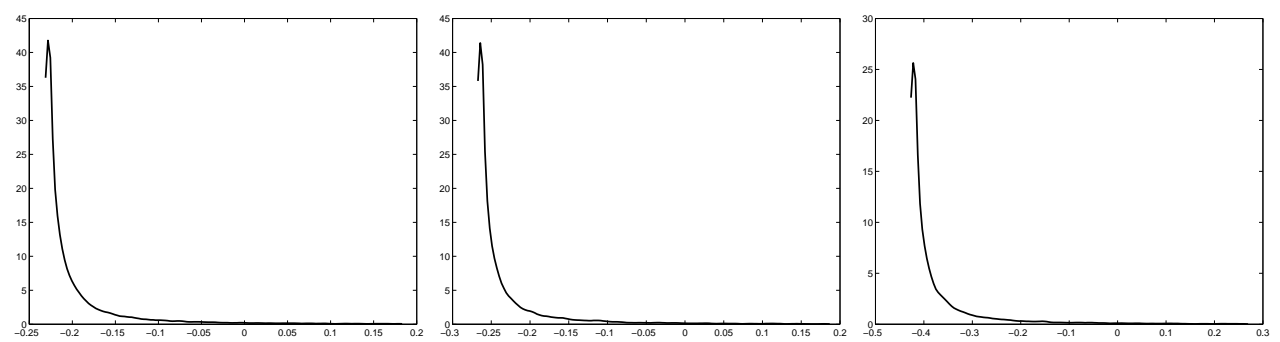

Figure 7: Volatility impulse response function of forward base returns in $t_{2}=07 / 10 / 03$ for a forecast horizon $h=1$. From left to right : $R_{t}^{\text {ger }}, R_{t}^{\text {nel }}$ and $R_{t}^{u k}$ variance
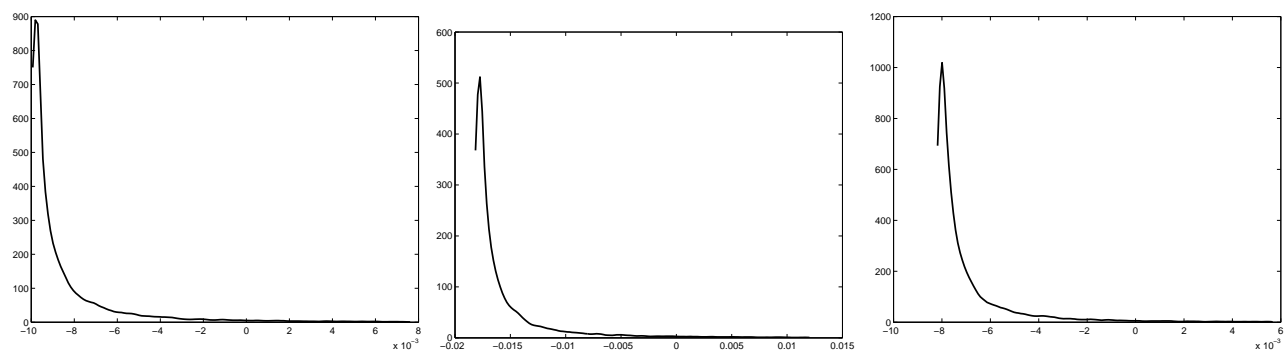

Figure 8: Volatility impulse response function of forward base returns in $t_{2}=07 / 10 / 03$ for a forecast horizon $h=20$. From left to right : $R_{t}^{\text {ger }}, R_{t}^{\text {nel }}$ and $R_{t}^{u k}$ variance

to shift to the left for the German and the Dutch returns and to the right for the British returns. Therefore, we can infer from these shifts that the probability of observing an increase in British expected conditional volatility is higher for peak returns. Another difference is that the impact of shocks on expected conditional volatilities is cancelling out less quickly. This lower speed of decrease is particularly striking in the case of the Dutch returns.
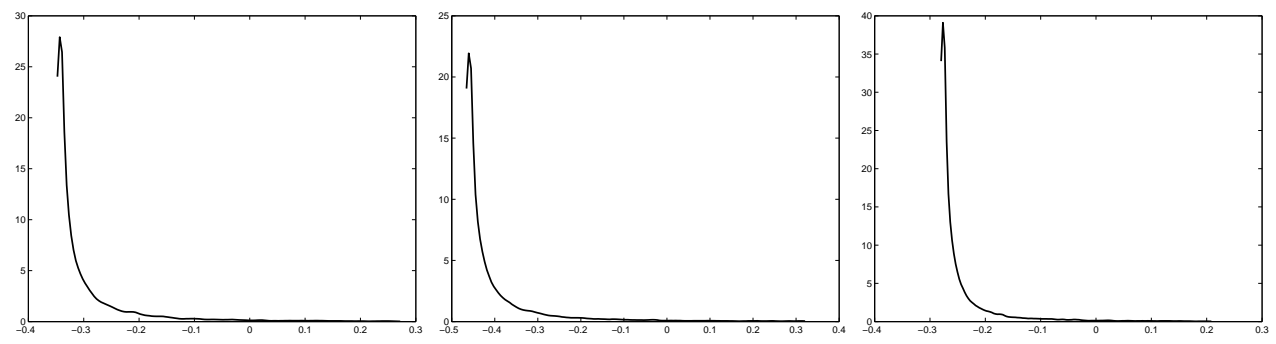

Figure 9: Volatility impulse response function of forward base returns in $t_{1}=07 / 09 / 03$ for a forecast horizon $h=1$. From left to right : $R_{t}^{\text {ger }}, R_{t}^{\text {nel }}$ and $R_{t}^{u k}$ variance
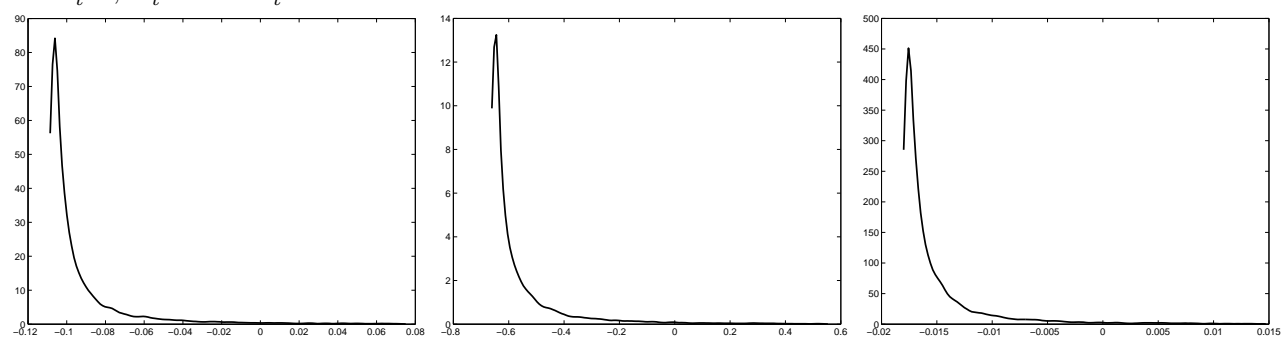

Figure 10: Volatility impulse response function of forward base returns in $t_{1}=07 / 09 / 03$ for a forecast horizon $h=20$. From left to right : $R_{t}^{g e r}, R_{t}^{n e l}$ and $R_{t}^{u k}$ variance

The estimated densities of the impact of a stochastic shock for the second date $t_{2}=07 / 10 / 03$ are 
depicted in graph 11 for a forecast horizon $h=1$ and graph 12 for $h=20$. They do not differ from the VIRF distribution for $t_{1}$ which indicates that the change in the history between these two dates has not a major impact on the VIRF distributions.
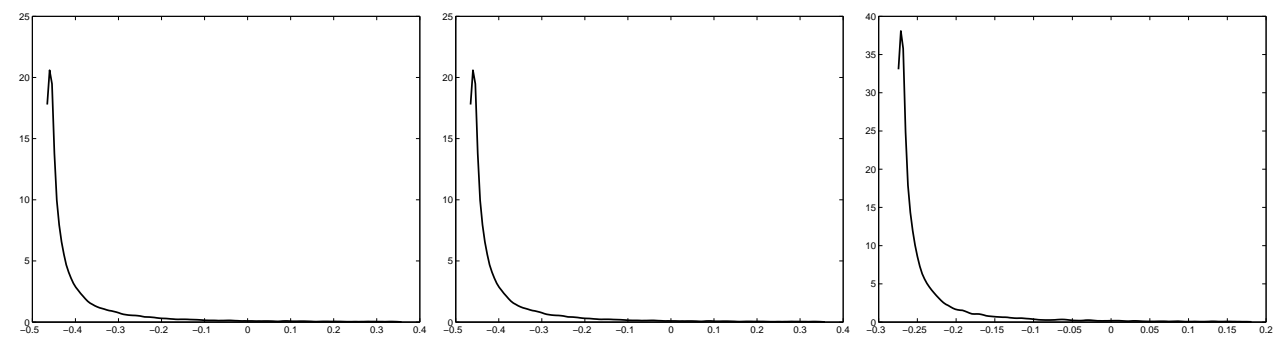

Figure 11: Volatility impulse response function of forward base returns in $t_{2}=07 / 10 / 03$ for a forecast horizon $h=1$. From left to right : $R_{t}^{g e r}, R_{t}^{\text {nel }}$ and $R_{t}^{u k}$ variance
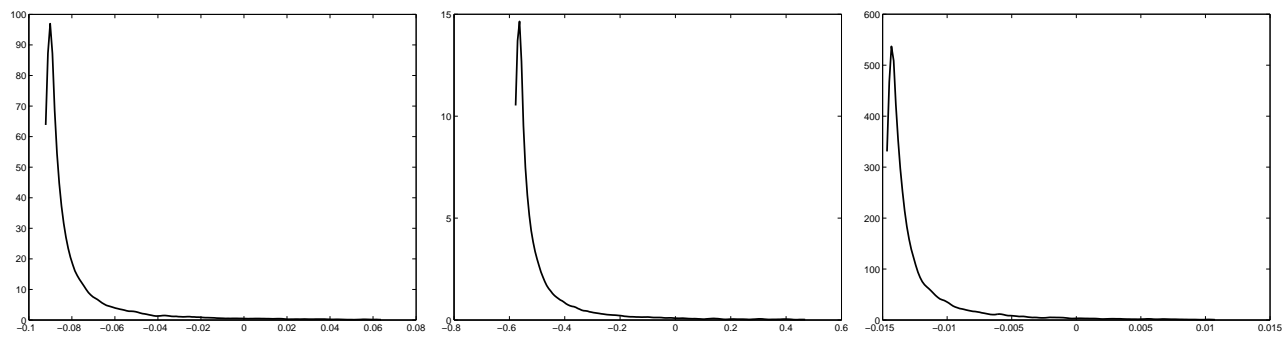

Figure 12: Volatility impulse response function of forward base returns in $t_{2}=07 / 10 / 03$ for a forecast horizon $h=20$. From left to right : $R_{t}^{g e r}, R_{t}^{\text {nel }}$ and $R_{t}^{u k}$ variance

\section{Conclusion}

A first result of this article is to show that the German, the Dutch and the British electricity forward markets are connected either by their returns or their volatilities. These connections mean that in explaining the changes in volatility in one market, the part of the other markets cannot be ruled out $a$ priori. Another consequence is that taking into account those spillovers should improve the accuracy of forecasts. The following step is to estimate the size of these connections through an impulse response analysis. Whereas impulse response analysis has mainly focused on the impact of shocks on the conditional mean of returns, we are interested in their impact on conditional variance. The volatility impulse response is measured by Hafner and Herwartz' (2006) VIRF. The VIRF measures the change in expected conditional covariance matrix induced by a shock, given history. A shock may lead to increase or decrease our expectation on future volatility given its size and history.

We use first observed historical shock and conditional covariance matrix to estimate the VIRF. These estimates produce two different pictures: for the first date, the impact is slightly negative while it is large and positive for the second date. The duration of the impact is smaller in base period. We also simulate random shocks drawn from the estimated data generating process to fit the VIRF distribution. These simulated random shocks are a way to produce realistic shocks. These distributions show that the probability of a high impact is low whereas it is high for a null or a negative one. These features denote a good efficiency and a good reaction to shocks from traders. An explanation could be the 
possibility of volatility arbitrages in different markets using derivatives products. Nevertheless, these findings also indicate the presence of beneficial strategies for energy traders, despite no evaluation of these strategies are provided in this paper.

An extension for this paper could also be to use very high frequency data (tick-by-tick) so that arbitrages may be more precisely detected. Unfortunately, in these OTC markets transparency is limited, and these data are generally not available.

The impulse response analysis could be used to describe the impact of shocks on correlations. This issue is particularly alive in the financial literature and related to the concept of contagion. Another area of research has recently been opened by Jondeau and Rockinger (2006) who analyse the impact of shocks on third and higher moments of a distribution. Options are known to be priced in reference to the skewness (and also higher moments), which could partly explain the so-called smile observed in the data. A better understanding of the impact of a shock on the conditional skewness of a set of markets could be valuable for traders. 
Table 1: Descriptive statistics of returns on forward prices at daily frequency

\begin{tabular}{lcccccc}
\hline \hline & \multicolumn{2}{c}{ Germany } & \multicolumn{2}{c}{ The Netherlands } & \multicolumn{2}{c}{ The United Kingdom } \\
\hline & peak & base & peak & base & peak & base \\
\hline Nb Obs & 1064 & 1064 & 1064 & 1064 & 1064 & 1064 \\
Mean & 0.000783 & 0.000681 & 0.000487 & 0.000501 & 0.000312 & 0.000389 \\
Median & 0.00 & 0.00 & 0.00 & 0.00 & -0.000693 & -0.000386 \\
Maximum & 0.321584 & 0.268929 & 0.524071 & 0.459803 & 0.401573 & 0.266325 \\
Minimum & -0.190354 & -0.174624 & -0.548566 & -0.501364 & -0.437298 & -0.229169 \\
Std. dev & 0.036632 & 0.028453 & 0.054252 & 0.056697 & 0.043066 & 0.028952 \\
Annual Vol & $57,92 \%$ & $44,99 \%$ & $85,78 \%$ & $89,64 \%$ & $68,09 \%$ & $45,77 \%$ \\
Skewness & 1.470332 & 1.331591 & -0.015168 & -0.512164 & 0.181725 & 0.866514 \\
Kurtosis & 20.62349 & 22.27280 & 39.24582 & 34.04719 & 33.85767 & 23.53480 \\
Jarque-Bera & $14152.75^{*}$ & $16781.64^{*}$ & $58243.38^{*}$ & $42780.66^{*}$ & $42219.86^{*}$ & $18827.54^{*}$ \\
\hline \hline
\end{tabular}

Note: ${ }^{*}$ denotes significance at a $5 \%$ level. 
Table 2: Estimates of the $\operatorname{VAR}(2)$ for base returns

\begin{tabular}{lccc}
\hline \hline & $R_{t}^{\text {ger }}$ & $R_{t}^{\text {nel }}$ & $R_{t}^{u k}$ \\
\hline $\mathrm{c}$ & 0.0006 & 0.0003 & 0.0002 \\
& $(0.69)$ & $(0.20)$ & $(0.32)$ \\
$R_{t-1}^{\text {ger }}$ & $0.104^{*}$ & $0.332^{*}$ & $0.079^{*}$ \\
& $(3.24)$ & $(5.39)$ & $(2.41)$ \\
$R_{t-2}^{\text {ger }}$ & $-0.082^{*}$ & -0.009 & 0.036 \\
& $(-2.53)$ & $(-0.15)$ & $(1.08)$ \\
$R_{t-1}^{n e l}$ & 0.008 & $-0.283^{*}$ & -0.018 \\
& $(0.52)$ & $(-9.18)$ & $(-1.08)$ \\
$R_{t-2}^{\text {nel }}$ & 0.020 & $-0.082^{*}$ & 0.009 \\
& $(1.26)$ & $(-2.69)$ & $(0.58)$ \\
$R_{t-1}^{u k}$ & $0.118^{*}$ & -0.052 & $0.092^{*}$ \\
& $(3.84)$ & $(-0.89)$ & $(2.92)$ \\
$R_{t-2}^{u k}$ & 0.047 & $0.334^{*}$ & -0.026 \\
& $(1.53)$ & $(5.65)$ & $(-0.84)$ \\
\hline$R^{2}$ & 0.038 & 0.115 & 0.020 \\
SE of regression & 0.027 & 0.053 & 0.028 \\
\hline \hline
\end{tabular}

Note: $\overline{\overline{\text { t-Student in parenthesis.* denotes significance at }}}$ a $5 \%$ level.

Table 3: Estimates of the $\operatorname{VAR}(2)$ for peak returns

\begin{tabular}{lccc}
\hline \hline & $R_{t}^{\text {ger }}$ & $R_{t}^{\text {nel }}$ & $R_{t}^{u k}$ \\
\hline $\mathrm{C}$ & 0.0007 & 0.0003 & 0.0001 \\
& $(0.69)$ & $(0.22)$ & $(0.14)$ \\
$R_{t-1}^{\text {ger }}$ & $0.103^{*}$ & $0.185^{*}$ & $0.141^{*}$ \\
$R_{t-2}^{\text {ger }}$ & $(3.11)$ & $(3.72)$ & $(3.53)$ \\
& -0.065 & 0.033 & 0.066 \\
$R_{t-1}^{n e l}$ & $(-1.94)$ & $(0.66)$ & $(1.67)$ \\
$R_{t-2}^{n e l}$ & $-0.062^{*}$ & $-0.118^{*}$ & -0.042 \\
& $(-2.84)$ & $(-3.60)$ & $(-1.62)$ \\
$R_{t-1}^{u k}$ & -0.033 & $-0.094^{*}$ & -0.032 \\
& $(-1.50)$ & $(-2.88)$ & $(-1.21)$ \\
$R_{t-2}^{u k}$ & $0.121^{*}$ & 0.037 & -0.047 \\
& $(4.59)$ & $(0.96)$ & $(-1.48)$ \\
\hline$R^{2}$ & $0.096^{*}$ & $0.113^{*}$ & 0.010 \\
$\mathrm{SE}$ of regression & $(3.63)$ & $(2.87)$ & $(0.33)$ \\
\hline \hline
\end{tabular}

Note: $\overline{\overline{\text { t-Student in parenthesis. }{ }^{*} \text { denotes significance at }}}$ a $5 \%$ level. 
Table 4: Estimates of $\operatorname{BEKK}(1,1)$ model for forward base returns with normal distribution $\epsilon_{t} \mid \psi_{t-1} \sim$ $N\left(0, \Sigma_{t}\right)$

\begin{tabular}{|c|c|c|c|c|c|c|c|c|}
\hline \multicolumn{3}{|c|}{$\overline{C_{0}}$} & \multicolumn{3}{|c|}{$\bar{A}$} & \multicolumn{3}{|c|}{$G$} \\
\hline $0.005^{*}$ & 0 & 0 & $0.467^{*}$ & $0.011^{*}$ & $0.060^{*}$ & $0.931^{*}$ & $-0.077^{*}$ & $-0.269^{*}$ \\
\hline$(5.93 \mathrm{e}-6)$ & (0) & (0) & $(0.011)$ & $(0.002)$ & $(0.008)$ & $(0.001)$ & $(0.005)$ & $(0.008)$ \\
\hline$-0.005^{*}$ & $0.031^{*}$ & 0 & $-0.124^{*}$ & $0.580^{*}$ & $-0.297^{*}$ & $0.424^{*}$ & $0.556^{*}$ & $-0.173^{*}$ \\
\hline$(3.59 \mathrm{e}-4)$ & $(3.42 \mathrm{e}-5)$ & (0) & $(0.054)$ & $(0.040)$ & $(0.140)$ & $(0.023)$ & $(0.015)$ & $(0.271)$ \\
\hline $0.014^{*}$ & $0.008^{*}$ & $-4.997 \mathrm{e}-6$ & -0.032 & $0.010^{*}$ & $0.670^{*}$ & $0.110^{*}$ & $-0.032^{*}$ & $0.535^{*}$ \\
\hline$(6.86 \mathrm{e}-5)$ & $(1.32 \mathrm{e}-4)$ & $(4.46 \mathrm{e}-6)$ & $(0.026)$ & $(0.002)$ & $(0.065)$ & $(0.004)$ & $(0.004)$ & $(0.039)$ \\
\hline $0.76+0.12 \mathrm{i}$ & $0.76-0.12 \mathrm{i}$ & $0.78+0.05 \mathrm{i}$ & $0.78-0.05 \mathrm{i}$ & $\begin{array}{l}\lambda_{i} \\
0.826\end{array}$ & 0.781 & 0.781 & $0.786+0.058 \mathrm{i}$ & $0.786-0.058 \mathrm{i}$ \\
\hline $\log \mathrm{L}$ & 6552 & & & & & & & \\
\hline
\end{tabular}

Table 5: Estimates of $\operatorname{BEKK}(1,1)$ model for forward base returns with Student distribution $\epsilon_{t} \mid$ $\psi_{t-1} \sim g\left(\Sigma_{t}^{-1 / 2}\right) \mid \Sigma_{t}^{-1 / 2}$

\begin{tabular}{|c|c|c|c|c|c|c|c|c|}
\hline \multicolumn{3}{|c|}{$\overline{\overline{C_{0}}}$} & \multicolumn{3}{|c|}{$\bar{A}$} & \multicolumn{3}{|c|}{$G$} \\
\hline $0.005^{*}$ & 0 & 0 & $0.457^{*}$ & $0.013^{*}$ & 0.065 & $0.932^{*}$ & $-0.079^{*}$ & $-0.270^{*}$ \\
\hline$(2.12 \mathrm{e}-6)$ & (0) & (0) & $(0.095)$ & $(0.002)$ & $(0.138)$ & $(0.005)$ & $(0.003)$ & $(0.004)$ \\
\hline$-0.005^{*}$ & $0.029 *$ & 0 & $-0.142^{*}$ & $0.573^{*}$ & -0.267 & $0.434^{*}$ & $0.555^{*}$ & -0.178 \\
\hline$(5.85 \mathrm{e}-5)$ & $(0.0001)$ & (0) & $(0.025)$ & $(0.035)$ & $(0.147)$ & $(0.041)$ & $(0.100)$ & $(0.158)$ \\
\hline $0.014 *$ & $0.008 *$ & $1.062 \mathrm{e}-5^{*}$ & $-0.019^{*}$ & 0.008 & $0.653^{*}$ & $0.110^{*}$ & $-0.034^{*}$ & $0.536^{*}$ \\
\hline$(3.90 \mathrm{e}-6)$ & $(2.83 \mathrm{e}-6)$ & $(5.24 \mathrm{e}-10)$ & (0.009) & ( 0.006$)$ & $(0.106)$ & $(0.007)$ & (0.001) & $(0.002)$ \\
\hline & & & & & & & & \\
\hline $0.75-0.12 \mathrm{i}$ & $0.75+0.12 \mathrm{i}$ & $0.76-0.05 \mathrm{i}$ & $0.76+0.05 \mathrm{i}$ & 0.81 & 0.77 & 0.77 & $0.77-0.06 \mathrm{i}$ & $0.77+0.06 \mathrm{i}$ \\
\hline $\log \mathrm{L}$ & 6912.5 & & & & & & & \\
\hline$\nu$ & 2.1 & & & & & & & \\
\hline
\end{tabular}

Note: standard errors in parenthesis. Log $\mathrm{L}$ is the value of the log-likelihood. The $\lambda_{i}$ are the eigen-

values of the matrix $A \otimes A+G \otimes G . \nu$ is the estimated degree of freedom of the Student distribution.

$*$ denotes significance at a $5 \%$ level.

Table 6: Estimates of $\operatorname{BEKK}(1,1)$ model for forward peak returns with normal distribution $\epsilon_{t} \mid \psi_{t-1} \sim$ $N\left(0, \Sigma_{t}\right)$

\begin{tabular}{|c|c|c|c|c|c|c|c|c|}
\hline \multicolumn{3}{|c|}{$\overline{C_{0}}$} & \multicolumn{3}{|c|}{$\bar{A}$} & \multicolumn{3}{|c|}{$\bar{G}$} \\
\hline $0.008^{*}$ & 0 & $\overline{0}$ & $0.567^{*}$ & 0.005 & $0.124^{*}$ & $0.856^{*}$ & $-0.031^{*}$ & $-0.268^{*}$ \\
\hline$(9.19 \mathrm{e}-6)$ & (0) & (0) & $(0.012)$ & (0.002) & $(0.006)$ & $(0.004)$ & $(0.001)$ & $(0.002)$ \\
\hline $0.013^{*}$ & $0.013^{*}$ & 0 & $0.180^{*}$ & $0.667^{*}$ & $-0.073^{*}$ & -0.003 & $0.786^{*}$ & $-0.134^{*}$ \\
\hline$(3.23 \mathrm{e}-5)$ & $(4.96 \mathrm{e}-5)$ & (0) & (0.009) & $(0.046)$ & $(0.005)$ & $(0.007)$ & $(0.006)$ & $(0.009)$ \\
\hline $0.025^{*}$ & $-0.010^{*}$ & $0.002 *$ & $-0.043^{*}$ & $0.013^{*}$ & $0.527^{*}$ & $0.132^{*}$ & 0.002 & $0.595^{*}$ \\
\hline$(1.16 \mathrm{e}-4)$ & $(1.68 \mathrm{e}-4)$ & $(3.43 \mathrm{e}-3)$ & $(0.009)$ & $(0.009)$ & $(0.055)$ & $(0.002)$ & $(0.002)$ & $(0.012)$ \\
\hline \multicolumn{9}{|c|}{$\lambda_{i}$} \\
\hline $0.76+0.07 i$ & $0.76-0.07 \mathrm{i}$ & $0.87+0.04 \mathrm{i}$ & $0.87-0.04 \mathrm{i}$ & 0.88 & 0.97 & $0.98+0.08 \mathrm{i}$ & $0.98-0.08 \mathrm{i}$ & 1.01 \\
\hline $\log \mathrm{L}$ & 5994.8 & & & & & & & \\
\hline
\end{tabular}

Note: standard errors in parenthesis. Log L is the value of the log-likelihood. The $\lambda_{i}$ are the eigenvalues of the matrix $A \otimes A+G \otimes G$. ${ }^{*}$ denotes significance at a $5 \%$ level. 
Table 7: Estimates of $\operatorname{BEKK}(1,1)$ model for forward peak returns with Student distribution $\epsilon_{t}$ $\psi_{t-1} \sim g\left(\Sigma_{t}^{-1 / 2}\right) \mid \Sigma_{t}^{-1 / 2}$

\begin{tabular}{|c|c|c|c|c|c|c|c|c|}
\hline \multicolumn{3}{|c|}{$C_{0}$} & \multicolumn{3}{|c|}{$A$} & \multicolumn{3}{|c|}{$\bar{G}$} \\
\hline $0.0086^{*}$ & 0 & 0 & 0.560 & $-7.68 \mathrm{e}-4$ & $0.115^{*}$ & $0.852^{*}$ & $-0.029^{*}$ & $-0.255^{*}$ \\
\hline$(3.59 \mathrm{e}-5)$ & (0) & (0) & $(0.349)$ & $(0.019)$ & $(0.007)$ & $(0.006)$ & $(0.009)$ & $(0.004)$ \\
\hline $0.012^{*}$ & $0.012^{*}$ & 0 & 0.195 & $0.592^{*}$ & -0.062 & -0.025 & $0.808^{*}$ & $-0.137^{*}$ \\
\hline$(2.52 \mathrm{e}-5)$ & $(3.78 \mathrm{e}-5)$ & $(0)$ & $(0.155)$ & $(0.232)$ & $(0.099)$ & $(0.030)$ & $(0.015)$ & $(0.006)$ \\
\hline $0.019^{*}$ & $-0.005^{*}$ & $0.016^{*}$ & -0.027 & 0.007 & 0.529 & $0.127^{*}$ & 0.004 & $0.600^{*}$ \\
\hline$(6.70 \mathrm{e}-5)$ & $(2.57 \mathrm{e}-6)$ & $(2.97 \mathrm{e}-5)$ & $(0.021)$ & $(0.013)$ & $(0.322)$ & $(0.020)$ & $(0.003)$ & $(6.47 \mathrm{e}-4)$ \\
\hline $0.77+0.08 \mathrm{i}$ & $0.77-0.08 \mathrm{i}$ & 0.86 & 0.88 & $\begin{array}{c}\lambda_{i} \\
0.89+0.05 \mathrm{i}\end{array}$ & $0.89-0.05 \mathrm{i}$ & $0.93+0.09 i$ & $0.93-0.09 \mathrm{i}$ & 0.98 \\
\hline
\end{tabular}

\begin{tabular}{cc}
\hline $\log \mathrm{L}$ & 6417.9 \\
$\nu$ & 2.10 \\
\hline & Note: \\
\hline
\end{tabular}

Note: standard errors in parenthesis. Log L is the value of the log-likelihood. The $\lambda_{i}$ are the eigenvalues of the matrix $A \otimes A+G \otimes G . \nu$ is the estimated degree of freedom of the Student distribution.

$*$ denotes significance at a $5 \%$ level. 


\section{References}

Barlow, M.T., 2002. A diffusion model for electricity prices. Mathematical Finance 12, 287-298.

Bessembinder, H., Lemmon, M.L., 2002. Equilibrium pricing and optimal hedging in electricity forward markets. Journal of Finance 2002, 1347-1382.

Boisseleau, F., 2004. The role of power exchanges for the creation of a single European electricity market: market design and market regulation. Thèse pour le doctorat en Sciences Économiques, Université Paris IX Dauphine, Paris.

Booth, G.G., Chowdhury, M., Martikainen, T., Tse, Y., 1997. Intraday volatility in international stock index futures markets: Meteor showers or heat waves? Management Science 43, 1564-1576.

Borenstein, S., 2002. The trouble with electricity markets: understanding California's restructuring disaster. Journal of Economic Perspectives 16, 191-211.

Bosco, B., Parisio, L., Pelagatti, M., Baldi, F., 2006. Deregulated wholesale electricity prices in Europe. Mimeo, Università di Milano-Bicocca.

Bosco, B., Parisio, L., Pelagatti, M., Baldi, F., 2007. A robust multivariate long run analysis of European electricity prices. Nota di Lavoro 103.2007, November, International Energy Markets series, Fondazione Eni Enrico Mattei, Milano.

Bower, J., 2002. Seeking the single European electricity market - Evidence from an empirical analysis of wholesale market prices. Working Paper EL01, Oxford Institute for Energy Studies.

BüHler, W., Müller-Merbach, J., 2007. Valuation of electricity futures: reduced-form vs. dynamic equilibrium models. Unpublished manuscript.

Bunn, D.W., (Eds) 2004. Modelling Prices in Competitive Electricity Markets. Wiley Finance, Chichester, UK.

Byström, H.N.E., 2005. Extreme value theory and extremely large electricity price changes. International Review of Economics and Finance 14, 41-55.

Dempster, G., Isaacs, J., Smith, N., 2008. Price discovery in restructured electricity markets. Resource and Energy Economics 30, 250-259.

De Vany, A.S., Walls, W.D., 1999. Cointegration analysis of spot electricity prices: insights on transmission efficiency in the western US. Energy Economics 21, 435-448.

EmerY, G.W., LiU, Q., 2002. An analysis of the relationship between electricity and natural-gas futures prices. Journal of Futures Markets 22, 95-122.

Engle, R.F., Ito, T., Lin, W.-L., 1990. Meteor showers or heat waves? Heteroskedastic intra-day volatility in the foreign exchange market. Econometrica 58, 525-542.

Engle, R.F., Kroner, F.K., 1995. Multivariate simultaneous generalized ARCH. Econometric Theory 11, 122-150.

Engle, R.F., NG, V.K., 1993. Measuring and testing the impact of news on volatility. Journal of Finance 48, 1749-1778.

Escribano, Á., Ignacio, J., Villaplana, P., 2002. Modeling electricity prices: international evidence. Working Paper 02-27, Economic Series 08, Universidad Carlos III de Madrid.

Ewing, B.T., Malik, F., Ozfidan, O., 2002. Volatility transmission in the oil and natural gas markets. Energy Economics $24,525-538$.

Eydeland, A., Geman, H., 1998. Pricing power derivatives. Risk 11, 71-73.

Figlewski, S., 1984. Hedging performance and basis risk in stock index futures. Journal of Finance 39, 657-669.

Fiorentini, G., Sentana, E., Calzolari, G., 2004. On the validity of the Jarque-Bera normality test in conditionally heteroskedastic dynamic regression models. Economics Letters 83, 307-312.

Fleming, J., Kirby, C., Ostdiek, B., 2001. The economic value of volatility timing. Journal of Finance 56, 329-352.

Fleming, J., Kirby, C., Ostdiek, B., 2003. The economic value of volatility timing using "realized" volatility. Journal of Financial Economics 67, 473-509.

Gallant, A.R., Rossi, P.E., Tauchen, G., 1993. Nonlinear dynamic structures. Econometrica 61, 871-907.

Geman, H., Roncoroni, A., 2006. Understanding the fine structure of electricity prices. Journal of Business 79, 1225-1261.

Goto, M., Karolyi, A., 2004. Understanding electricity price volatility within and across markets. Ohio State University Working Paper.

HADSELl, L., 2006. A TARCH examination of the return volatility-volume relationship in electricity futures. Applied Financial Economics 16, 893-901.

Hadsell, L., Marathe, A., Shawky, H.A., 2004. Estimating the volatility of wholesale electricity spot prices in the US. Energy Journal 25, 23-40. 
Hadsell, L., Shawky, H.A., 2006. Electricity price volatility and the marginal cost of congestion: an empirical study of peak hours on the NYISO market, 2001-2004. Energy Journal 27, 157-179.

Hafner, C.M., Herwartz, H., 2006. Volatility impulse responses for multivariate GARCH models: an exchange rate illustration. Journal of International Money and Finance 25, 719-740.

Hamao, Y., Masulis, R.W., NG, V., 1990. Correlations in price changes and volatility across international stock markets. Review of Financial Studies 3, 281-307.

Huisman, R., Huurman, C., Mahieu, R., 2007. Hourly electricity prices in day-ahead markets. Energy Economics 29, $240-248$.

Huisman, R., Mahieu, R., 2003. Regime jumps in electricity prices. Energy Economics 25, 425-434.

Jondeau, E., Rockinger, M., 2006. The impact of news on higher moments. HEC Lausanne Working Paper.

KAROLYI, G.A., 1995. A multivariate GARCH model of international transmissions of stock returns and volatility: the case of the United States and Canada. Journal of Business and Economic Statistics 13, 11-25.

Knittel, C.R., Roberts, M.R., 2005. An empirical examination of restructured electricity prices. Energy Economics 27, 791-817.

Koop, G.M., Pesaran, H.M., Potter, S.M., 1996. Impulse response analysis in nonlinear multivariate models. Journal of Econometrics 74, 119-147.

Koopman, S.J., Ooms, M., Carnero, M.A., 2007. Periodic seasonal Reg-ARFIMA-GARCH models for daily electricity spot prices. Journal of the American Statistical Association 102, 16-27.

Koutmos, G., Воотн, G.G., 1995. Asymmetric volatility transmission in international stock markets. Journal of International Money and Finance 14, 747-762.

LIN, W.-L., 1997. Impulse response function for conditional volatility in GARCH models. Journal of Business and Economic Statistics 15, 15-25.

Lin, W.-L., Engle, R.F., Ito, T., 1994. Do bulls and bears move across borders? International transmission of stock returns and volatility. Review of Financial Studies 7, 507-538.

Lucia, J., Schwartz, E.S., 2002. Electricity prices and power derivatives: evidence from the Nordic Power Exchange. Review of Derivatives Research 5, 5-50.

Mount, T.D., Ning, Y., CAI, X., 2006. Predicting price spikes in electricity markets using a regime-switching model with time-varying parameters. Energy Economics 28, 62-80.

Nelson, D.B., 1991. Conditional heteroskedasticity in asset returns. Econometrica 59, 347-370.

Park, H., Mjelde, J.W., Bessler, D.A., 2006. Price dynamics among U.S. markets. Energy Economics 28, 81-101.

Rambharat, R., Brockwell, A.E., Seppi, D.J., 2005. A threshold autoregressive model for wholesale electricity prices. Applied Statistics 54, 287-299.

Routledge, B.R., Seppi, D.J., Spatt, C.S., 2001. The spark spread: an equilibrium model of cross-commodity price relationships in electricity, Working Paper, Carnegie Mellon University.

Rusco, F.W., Walls, W.D., 2005. Modeling asymmetries and fat tails in power prices. Unpublished manuscript.

Schwartz, E., Smith, J.E., 2000. Short-term variations and long-term dynamics in commodity prices. Management Science $46,893-911$.

Serletis, A., Shahmoradi, A., 2006. Measuring and testing natural gas and electricity markets volatility: evidence from Alberta's deregulated markets. Studies in Nonlinear Dynamics \& Econometrics 10, 1-20.

Shields, K., Olekalns, N., Henry, Ó.T., Brooks, C., 2005. Measuring the Response of Macroeconomic Uncertainty to Shocks. Review of Economics and Statistics 87, 362-370.

Sims, C., 1980. Macroeconomics and reality. Econometrica 48, 1-48

Smeers, Y., 2004. Marchés organisés et marchés de gré à gré en électricité. Économie Publique 14, 3-21.

Strecker, S., Weinhardt, C., 2001. Wholesale electricity trading in the deregulated German electricity market - Results and insights from an empirical study. Mimeo, University of Karlsruhe.

Weron, R., 2006. Modeling and Forecasting Electricity Loads and Prices - A Statistical Approach. Wiley Finance, Chichester, UK.

Wilson, R., 2002. Architecture for power markets. Econometrica 70, 1299-1340.

Worthington, A., Kay-Spratley, A., Higgs, H., 2005. Transmission of prices and price volatility in Australian electricity spot markets: a multivariate GARCH analysis. Energy Economics 27, 337-350.

Zachmann, G., 2008. Electricity wholesale market prices in Europe: Convergence? Energy Economics 30, $1659-1671$.

Zakoian, J.-M., 1994. Threshold heteroskedastic models. Journal of Economic Dynamics and Control 18, 931-955. 


\section{Appendix A: returns series}
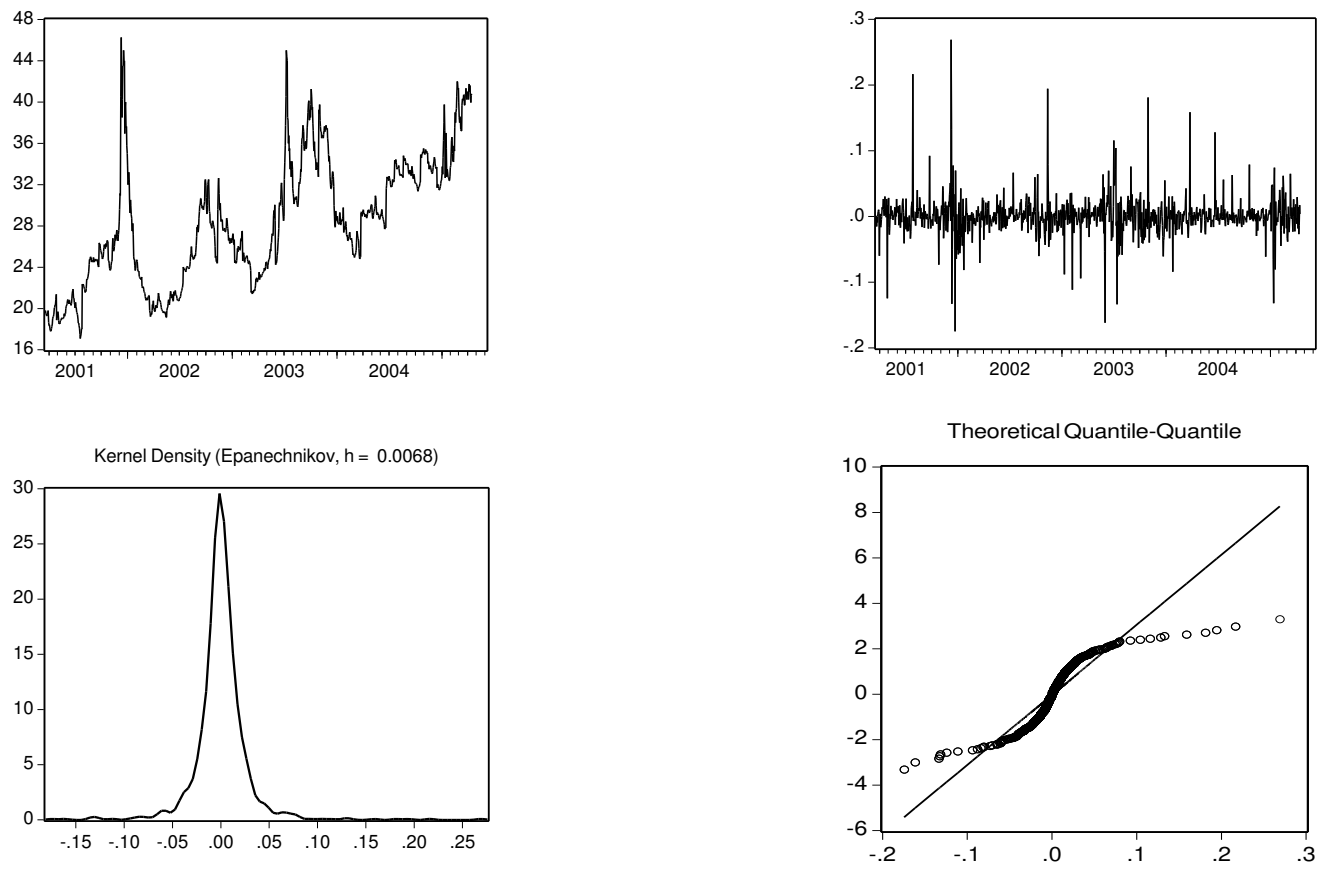

Figure 13: German base forward in level, first differences, kernel density and QQ-plot against the normal.
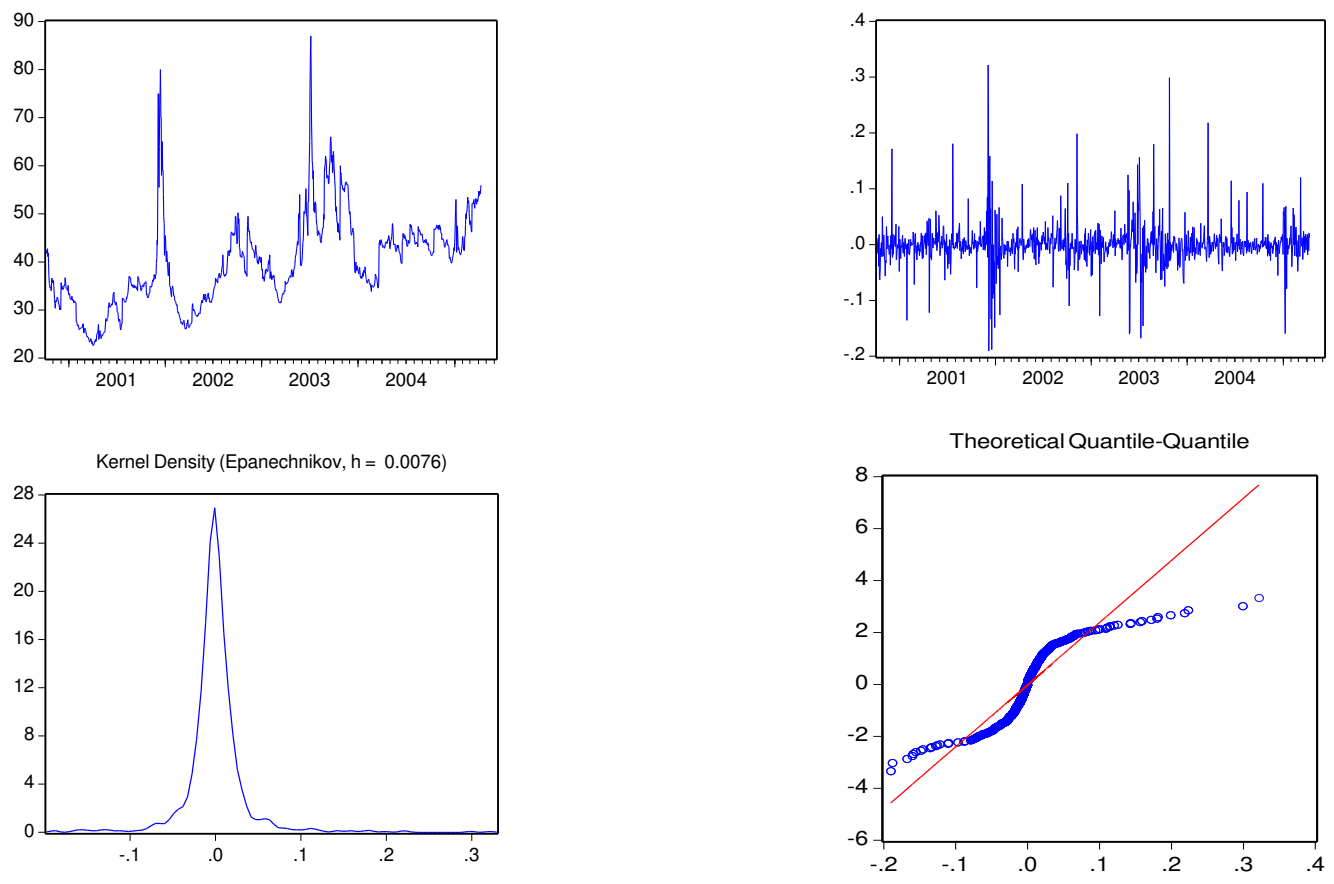

Figure 14: German peak forward in level, first differences, kernel density and QQ-plot against the normal. 

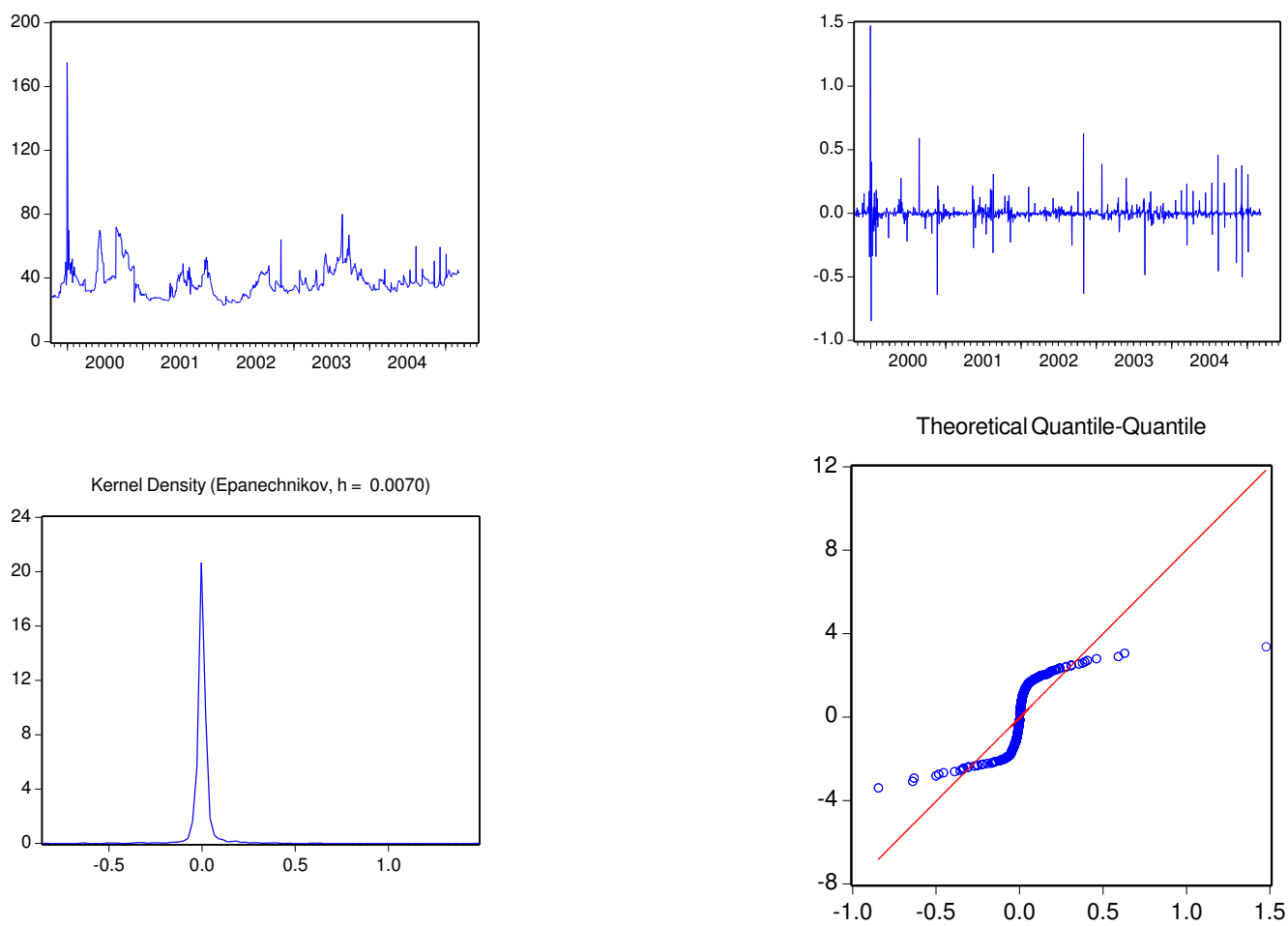

Figure 15: Dutch base forward price in level, first differences, kernel density and QQ-plot against the normal.
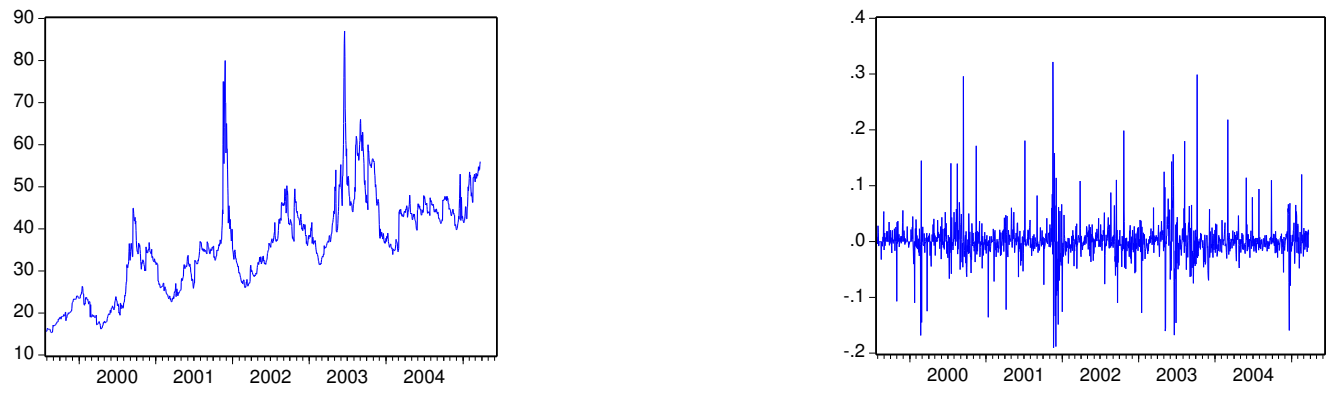

Theoretical Quantile-Quantile
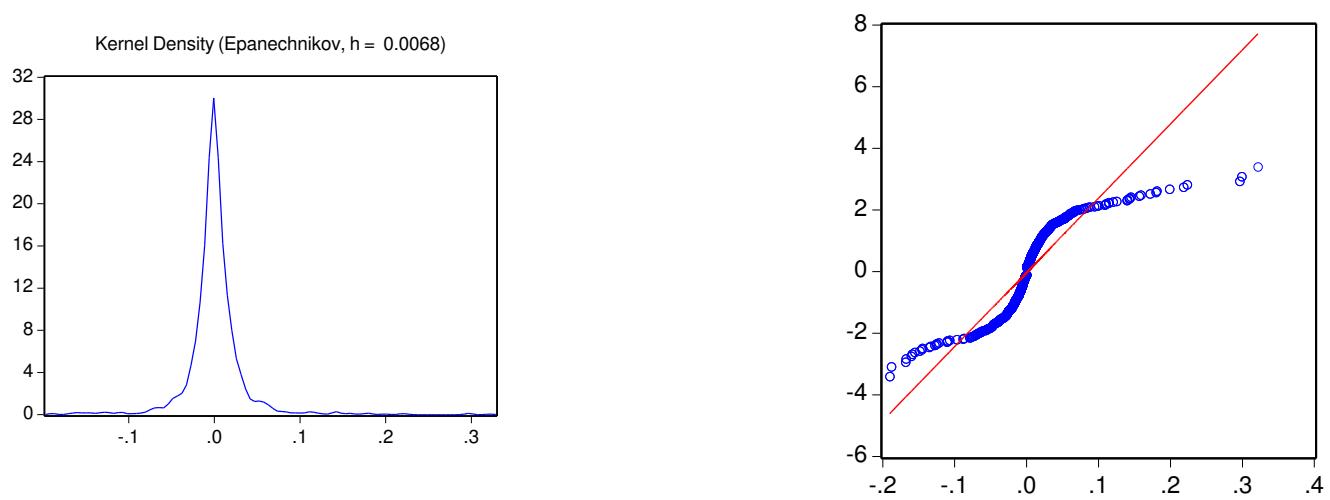

Figure 16: Dutch peak forward price in level, first differences, kernel density and QQ-plot against the normal. 

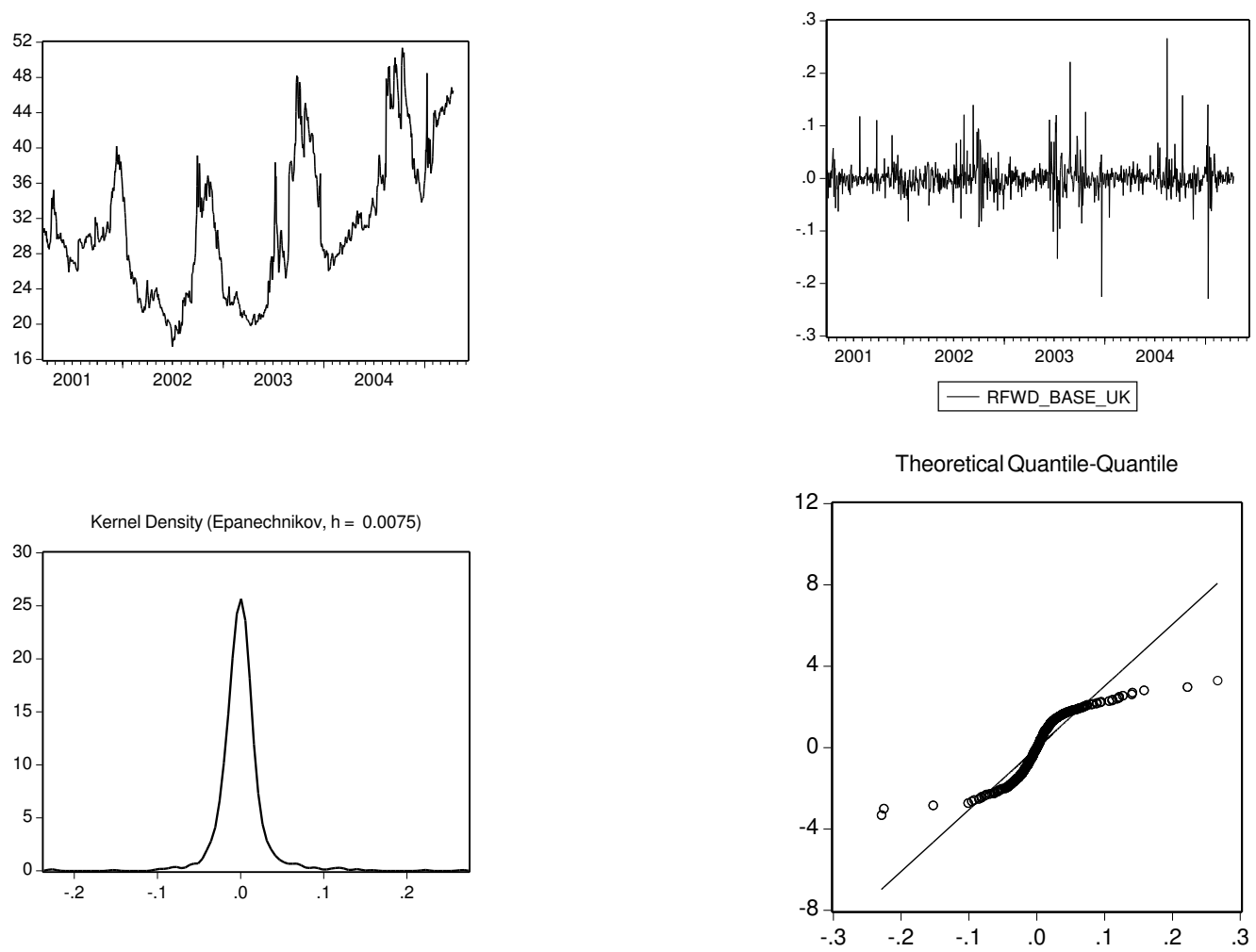

Figure 17: UK base forward in level, first differences, kernel density and QQ-plot against the normal.
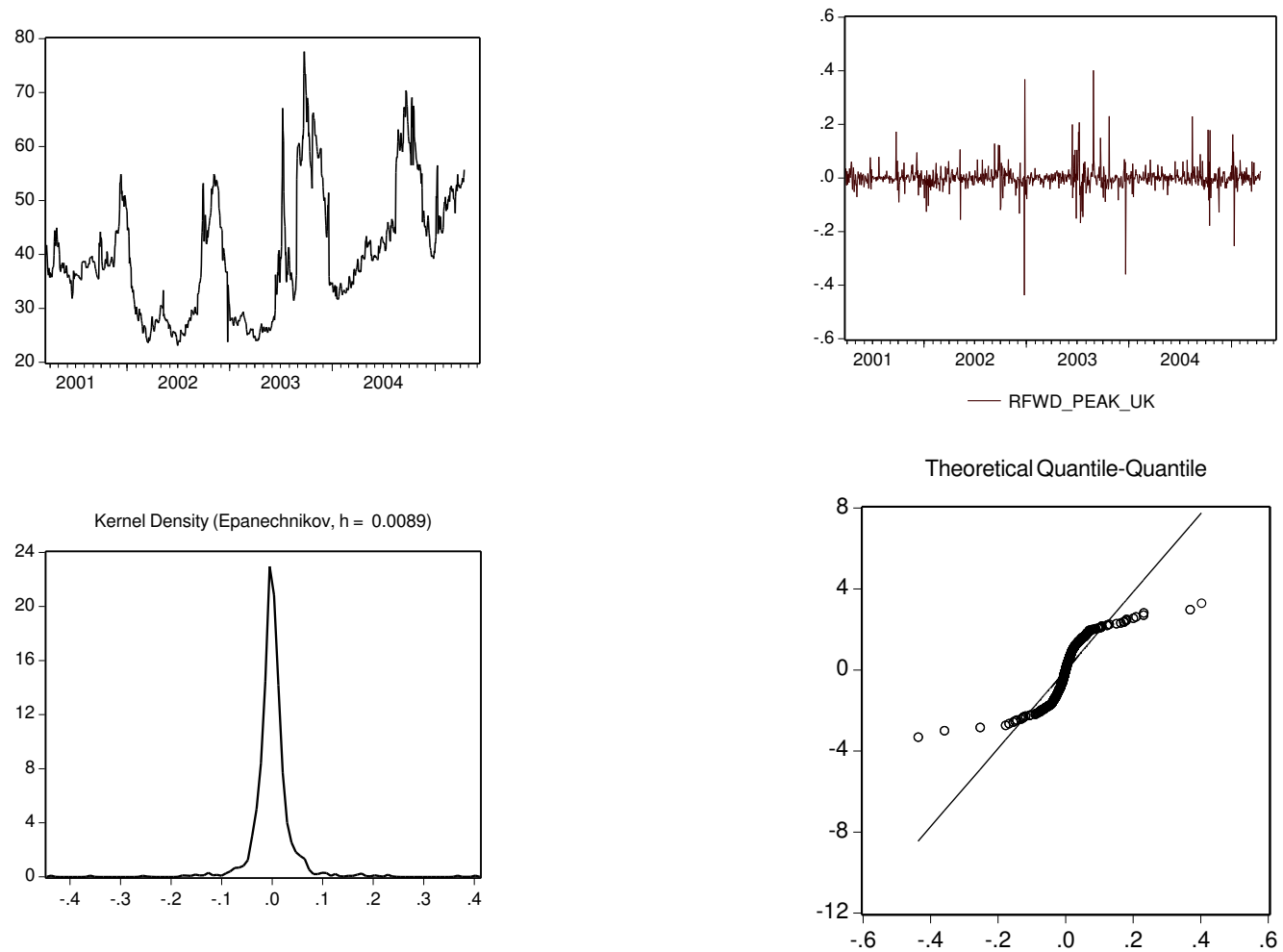

Figure 18: UK peak forward in level, first differences, kernel density and QQ-plot against the normal. 


\section{Appendix B: estimated conditional variances}
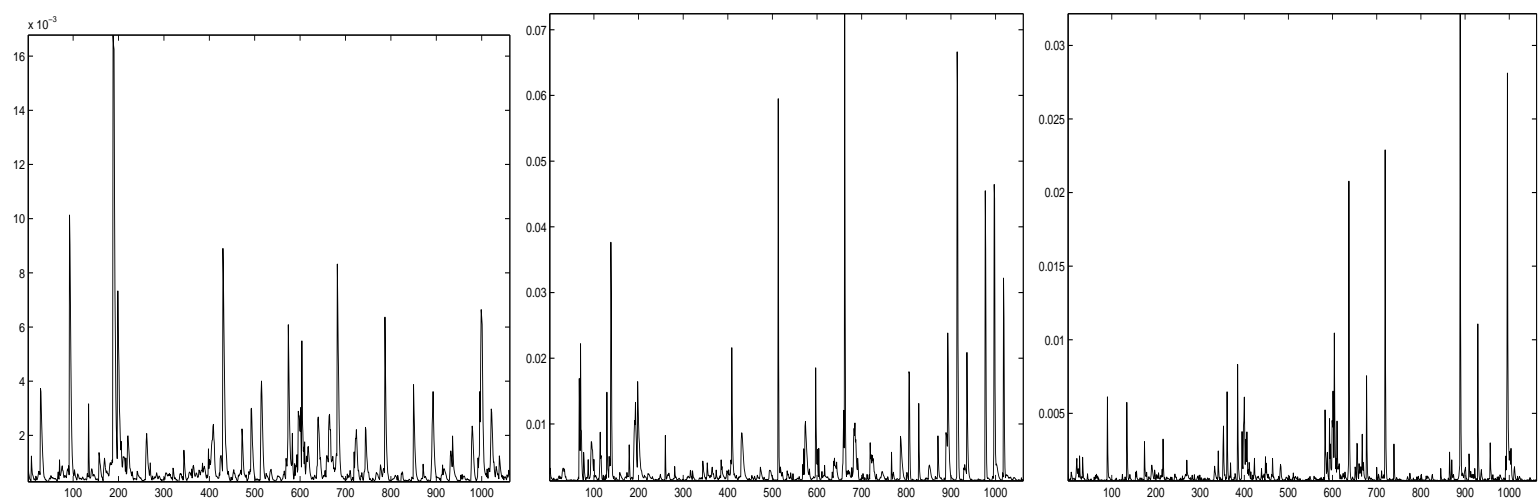

Figure 19: Estimated conditional volatilities of forward base returns. From left to right $: R_{t}^{g e r}, R_{t}^{n e l}$ and $R_{t}^{u k}$ variance
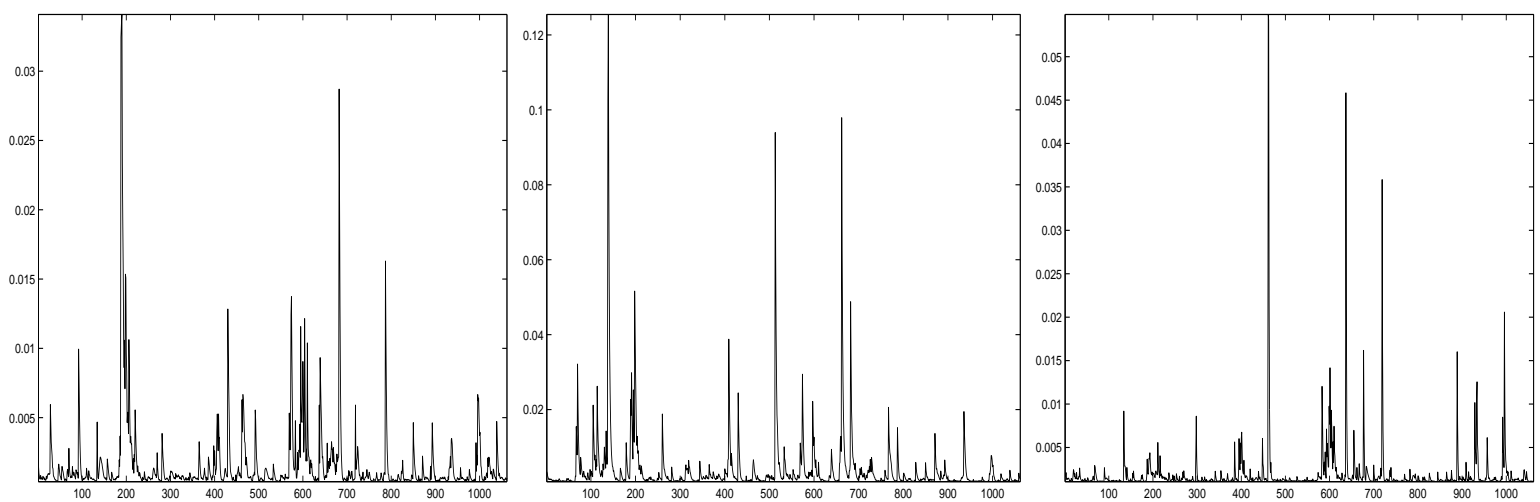

Figure 20: Estimated conditional volatilities of forward peak returns in $t_{1}=06 / 08 / 03$. From left to right $: R_{t}^{g e r}, R_{t}^{n e l}$ and $R_{t}^{u k}$ variance 
Les autres documents de travail du GRANEM accessibles sur le site Web du laboratoire à l'adresse suivante :

(www.univ-angers.fr/granem/publications) :

\begin{tabular}{|l|l|l|l|l|}
\hline Numéro & Titre & Auteur(s) & Discipline \\
\hline 2008-01-001 & $\begin{array}{l}\text { The Cognitive consistency, the endowment effect and the } \\
\text { preference reversal phenomenon }\end{array}$ & Serge Blondel, Louis Lévy-Garboua & Théorie du Risque & octobre 2008 \\
\hline 2008-02-002 & $\begin{array}{l}\text { Volatility transmission and volatility impulse response } \\
\text { functions in European electricity forward markets }\end{array}$ & Yannick Le Pen, Benoît Sévi & Econométrie Appliquée \\
\hline
\end{tabular}

